MANAGING ABNORMAL OPERATION THROUGH PROCESS INTEGRATION

\title{
AND COGENERATION SYSTEMS
}

\author{
A Thesis \\ by \\ SERVEH KAMRAVA
Submitted to the Office of Graduate and Professional Studies of Texas A\&M University
in partial fulfillment of the requirements for the degree of
MASTER OF SCIENCE

$\begin{array}{ll}\text { Chair of Committee, } & \text { Mahmoud El-Halwagi } \\ \text { Committee Members, } & \text { M. Sam Mannan } \\ & \text { Hisham Nasr-El-Din } \\ & \text { Fadwa T. Eljack } \\ \text { Head of Department, } & \text { M. Nazmul Karim }\end{array}$

August 2014

Major Subject: Safety Engineering

Copyright 2014 Serveh Kamrava 


\begin{abstract}
Flaring is a common industrial practice that leads to substantial greenhouse gas (GHG) emissions, health problems, and economic losses. When the causes, magnitudes, and frequency of flaring are properly understood and incorporated into the design and operation of the industrial plants, significant reduction in flaring can be achieved. In this paper, a process integration approach is presented to retrofit the process design to account for flaring and to consider the use of process cogeneration to mitigate flaring while gaining economic and environmental benefits. It is based on simultaneous design and operational optimization where key flaring sources, causes and consequences of process upsets are identified then included in the energy profile of the process to design a combined heat and power system with special emphasis on discontinuous sources due to process upset. Environmental and economic benefits are weighed against the cost of process retrofitting. A base case study for an ethylene process is used to illustrate the applicability of the proposed approach and to evaluate the process performance under varying abnormal situation scenarios. Finally some safety parameters for part of the process are reviewed.
\end{abstract}




\section{DEDICATION}

I would like to dedicate my work to my parents. 


\section{ACKNOWLEDGEMENTS}

I would like to acknowledge all the people who helped me in my graduate studies. First of all, I would like to express my sincere gratitude to my advisor, Dr. Mahmoud M. ElHalwagi and also to my committee member, Dr. Fadwa T. Eljack for their guidance, support and patience throughout my research. I would also like to thank Dr. Mannan and Dr. Nasr-El-Din for serving as my committee members.

I would like to thank my family and my fiancé for their support and love throughout this

journey. I would like to thank all my friends and specially Kerron J. Gabriel for his support and advice throughout this program.

I would like to recognize and thank the funding agency, Qatar National Research Fund (QNRF) for support through project number, NPRP 5-351-2-136. 


\section{TABLE OF CONTENTS}

Page

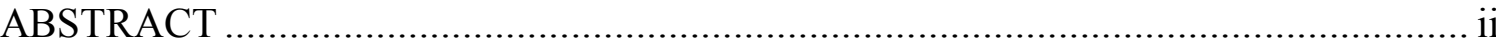

DEDICATION

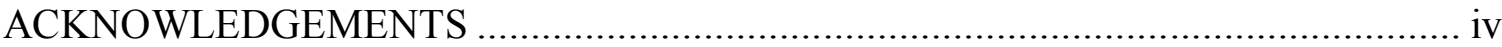

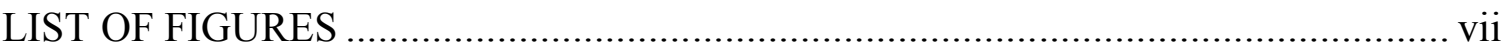

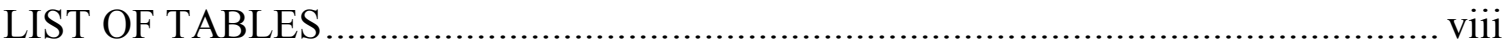

CHAPTER I INTRODUCTION ….................................................................... 1

CHAPTER II LITERATURE REVIEW ............................................................ 4

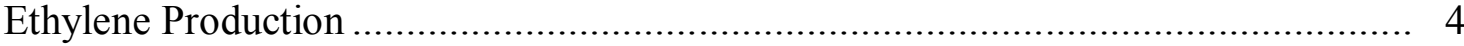

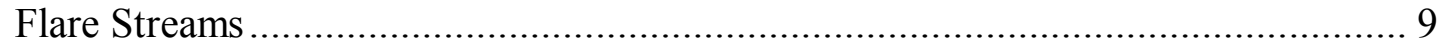

Case Study- Ethylene Process ....................................................................... 12

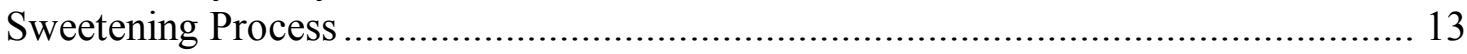

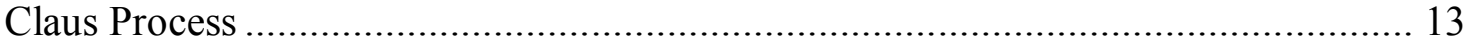

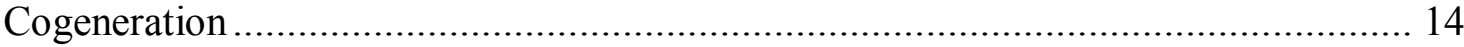

Types of Cogeneration Systems ................................................................. 16

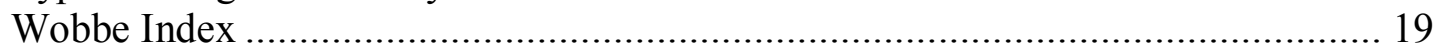

CHAPTER III ETHYLENE, SWEETENING AND CLAUS PROCESS MODELING . 21

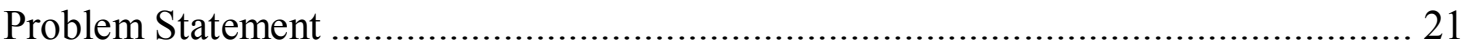

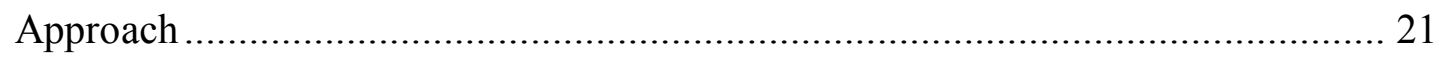

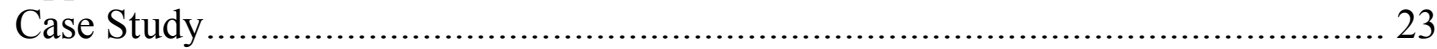

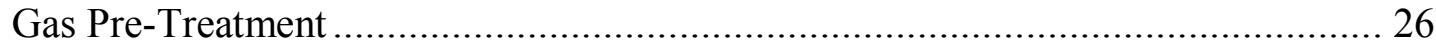

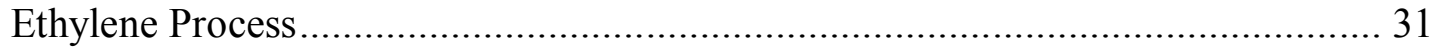

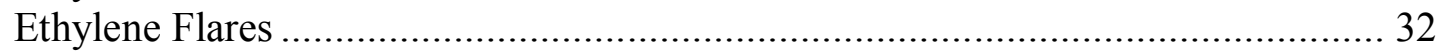

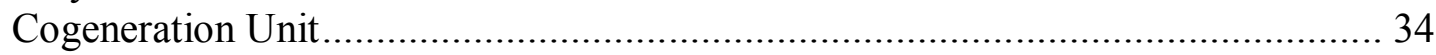

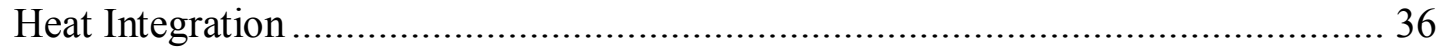

CHAPTER IV RESULTS AND ANALYSIS ..................................................... 41

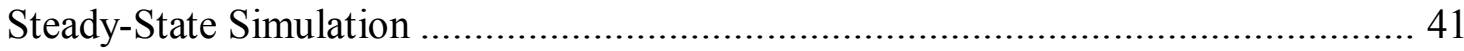

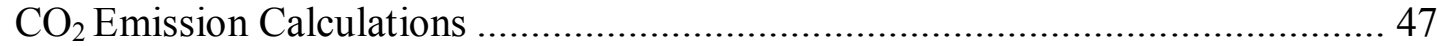

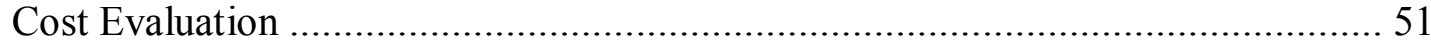




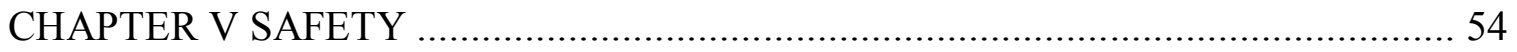

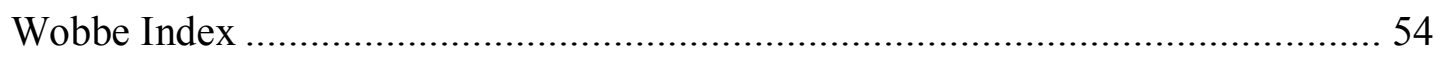

Flammability Limits ............................................................................ 57

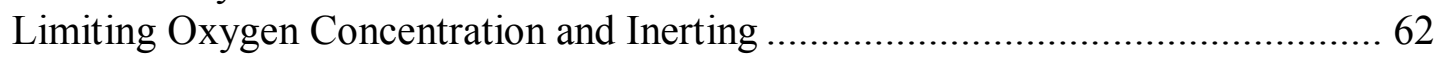

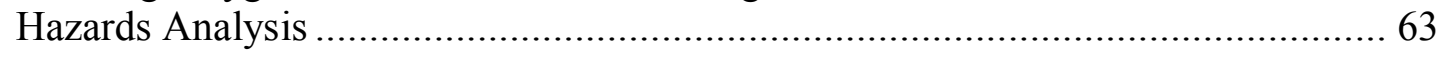

CHAPTER VI CONCLUSIONS AND RECOMMENDATIONS ............................... 69

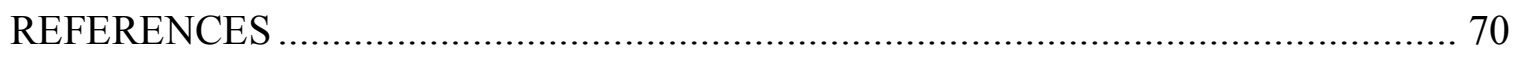




\section{LIST OF FIGURES}

Page

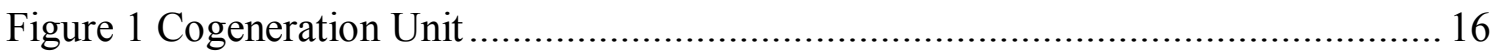

Figure 2 Approach to Manage Flares through Cogeneration ................................... 23

Figure 3 Selectivity of Ethylene versus Ethane Conversion (Dar, Nanot et al. 2012) .... 24

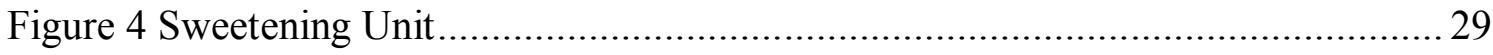

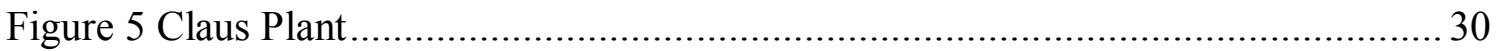

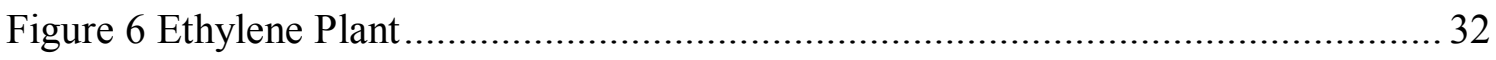

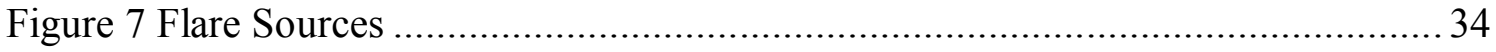

Figure 8 Temperature Interval Diagram for Ethylene Plant Case Study ...................... 38

Figure 9 Cascade Diagram for Ethylene Plant .................................................. 40

Figure 10 Ethylene Process Inlet and Outlet Streams in Yellow and Red, Respectively 44

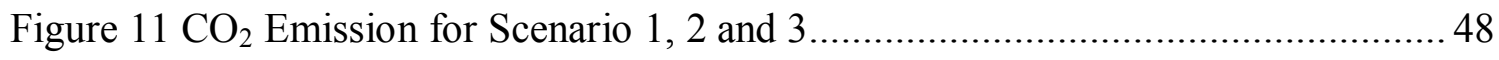

Figure $12 \mathrm{CO}_{2}$ Emission for Scenario 1, 2 and 3 from Different Sources .................... 49

Figure 13 Comparison of Three Different Methods for WI of Different Flare Streams . 56

Figure 14 Cogeneration System Utilizing Mixed Fuels ..................................... 57

Figure 15 Dependency of LFL and UFL of Stream A, B and A+B versus Temperature 61

Figure 16 UFL of Stream A (--), B (--) and C (--) versus Pressure (atm)................... 62

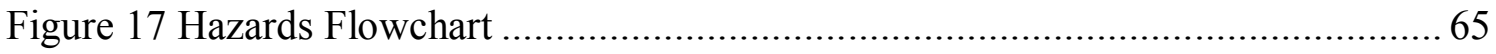




\section{LIST OF TABLES}

Table 1 Summary of Some Main Reactions in Cracking Furnace ................................ 8

Table 2 Results of Ethane Pyrolysis in Uniform Temperature (Dar, Nanot et al. 2012). 25

Table 3 Inlet Feed Stream Properties to Sweetening Unit .................................... 27

Table 4 Claus Process Heat Streams................................................................... 30

Table 5 Properties of Inlet Stream of Claus Process ............................................ 31

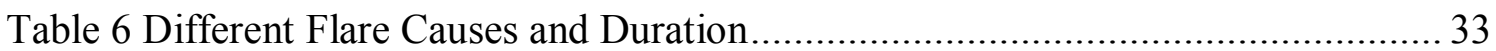

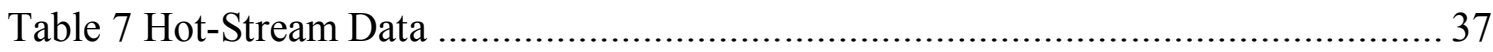

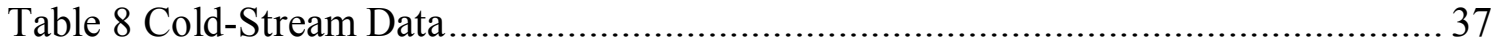

Table 9 TEHL for Hot Streams in Ethylene Plant ............................................. 38

Table 10 TEHL for Cold Streams in Ethylene Plant .............................................. 39

Table 11 Ethylene Process Stream Data ............................................................... 42

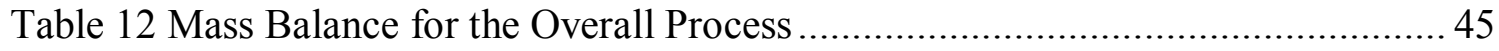

Table 13 Properties of Flare Streams ................................................................... 46

Table 14 Total Heat Requirement in Ethylene, Sweetening and Claus Process ............ 46

Table 15 Power Requirement in the Ethylene Process ........................................ 46

Table 16 Output of Cogeneration System ....................................................... 47

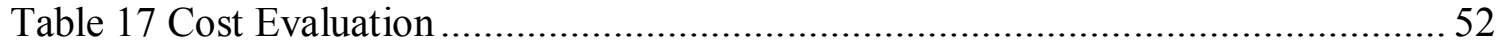

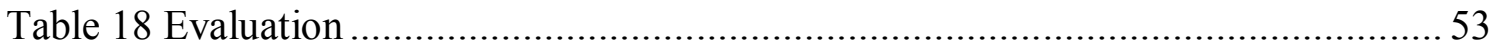

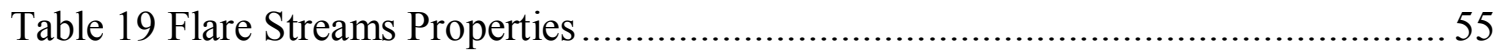

Table 20 Mole Fraction and Flammability Limit vol. \% Fuel in air of Flare Streams .... 59 
Table 21 LFL and UFL, FR and Heat of Combustion for Flare Streams ..................... 60

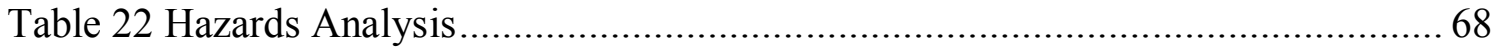




\section{CHAPTER I}

\section{INTRODUCTION*}

Flaring in industrial processes is recognized as the cause of several environmental and cost issues with multiple implications. Flaring results economic losses, waste of limited material and energy resources, generation of significant amounts of $\mathrm{CO}_{2}$ and other greenhouse gas (GHG) emissions affecting air quality and contributing to global warming. There is also a noticeable impact on local populations living close to industrial sites. Flaring affects their quality of life and health. Yearly, around 140 billion cubic meters of natural gas are flared globally, the equivalent of 281 million tons $\mathrm{CO}_{2}$ emissions (Davoudi, Rahimpour et al. 2013). The numbers seem large in magnitude but the impact is even larger when considering that 400 million tons of $\mathrm{CO}_{2}$ emissions per year equal the annual emission rate of 77 million cars. In terms of economics, the loss is about $\$ 10-15$ billion/year based on gas prices of $\$ 2$ to $\$ 3$ per MMBTU (Farina 2010).

Why do companies flare in the first place? It is a common practice in process operation to flare under abnormal situations as a safety precaution in order to protect the operators and the plant facility. It is also a standard operational procedure to flare during plant upsets, such as equipment malfunction, off-spec production, depressurization of gas processing equipment, startup, or emergency shutdowns. Additionally, flaring is used to

\footnotetext{
"Part of this chapter is reprinted with permission from "Managing abnormal operation through process integration and cogeneration systems" by Serveh Kamrava, Kerron J. Gabriel, Mahmoud M. ElHalwagi, Fadwa T. Eljack, 2014. Clean Technologies and Environmental Policy, pg. 1-10, Copyright [2014] by Springer Science+ Business Media”
} 
dispose of flammable gases that are either unusable or uneconomical to recover. Similar to flaring in its environmental and economic impact, the venting of process gases is also a major concern. It occurs in industry to release unwanted gases and for safer operation of process equipment such as in the case of relieving buildup pressure. Flaring often leads to high emissions of combustion products and unreacted fuels. In natural gas processing, examples of these emissions include GHGs such as methane, $\mathrm{NO}_{\mathrm{x}}, \mathrm{SO}_{\mathrm{x}}$, and $\mathrm{CO}_{2}$. It is also worth noting that most of the flaring of associated gas from oil production or direct gas venting is a key source of concern that industry must address by better operational practices. With rising energy and feedstock prices and growing stringency of environmental regulations, industry has motivation to better manage flaring and venting.

An important option for managing flaring and venting is the use of process cogeneration systems. Generating electrical and thermal energy simultaneously in a single integrated system is known as cogeneration. The combined efficiency of traditional methods of generating power and heat separately can be substantially enhanced using cogeneration systems. Furthermore, cogeneration increases the cost-effectiveness of the energy systems and reduces the $\mathrm{CO}_{2}$ emission (Deneux, Hafni et al. 2013). A common unit in cogeneration systems is the steam turbine which is one of the oldest technologies with typical capacity ranges from $50 \mathrm{KW}$ to $250 \mathrm{MW}$. Steam turbines have high efficiencies and lower costs and higher flexibility in the type of fuel used to generate the steam. They also have long working life and high reliability. Since most flared and vented gases contain combustible hydrocarbons, it is possible to use the heating value in these streams to generate steam that can be used for combined heat and power. The key here is to tie 
the cogeneration system design to the process energy profile and thermal loads. This can be optimized through a process integration framework.

The objective of the research is to develop an integrated framework for managing process flares by including them with the other process energy and thermal profiles in order to design a cogeneration system. The causes, extent, characteristics, and duration of flaring are accounted for in the design procedure. A cost-benefit analysis is used to establish the tradeoffs between economic and environmental benefits versus the cost of process revamping. An ethylene process is selected as the base case because of its industrial importance and because of the common flaring practices in this process worldwide. 


\title{
CHAPTER II
}

\section{LITERATURE REVIEW*}

\author{
Ethylene Production
}

Ethylene is a well-known and important petrochemical product and intermediate. Global capacity of ethylene has risen to $141 \mathrm{MMtons} / \mathrm{yr}$ in 2012 (Fu and $\mathrm{Xu} 2013$ ). Among different feedstock, ethylene produced from ethane in US has increased from $55 \%$ in 2007 to $71 \%$ in 2012 . This is partly attributed to the economic benefits of using ethane over the alternative heavy fuels (naptha) as a feedstock for ethylene production (Lippe 2013).

There are different methods that are being used for producing ethylene in industry. These methods are capable of applying different fuels for producing the target product (ethylene) and also these methods have differences in the separation which result in different ethylene production efficiency, energy requirement, environmental impact and initial and operating costs and etc. Some of the methods being applied for producing ethylene are: Technip, Kellogg Brown \& Root (KBR), ABB Lummus Global SRT cracking, Stone \& Webster Company, Linde company method.

\footnotetext{
"Part of this chapter is reprinted with permission from "Managing abnormal operation through process integration and cogeneration systems" by Serveh Kamrava, Kerron J. Gabriel, Mahmoud M. ElHalwagi, Fadwa T. Eljack, 2014. Clean Technologies and Environmental Policy, pg. 1-10, Copyright [2014] by Springer Science+ Business Media"
} 
In Technip method pyrolysis of hydrocarbons with steam (from ethane to gasoline) is used for producing ethylene and propylene. Feed stock is gas (ethane, propane) and liquid $\left(\mathrm{C}_{4}\right.$, naphta, gasoline). Ethylene production efficiency for various feed stocks is different. For example from ethane it is approximately $83 \%$, from naphta $35 \%$, from gasoline $25 \%$.

In KBR method, cracking process with high efficiency steam is used. The feed stock could be different hydrocarbons from ethane to vacuum gas oil. Ethylene efficiency depends on the feedstock. For ethane feedstock, efficiency is $84 \%$, for naphta is $38 \%$ and for gasoline is $32 \%$.

In ABB Lumus method ethylene is produced with $95.99 \%$ purity. In this process, ethane feedstock units have the lowest total capacity investment.

Stone \& Webster method employs thermal cracking of paraffin feedstock for producing ethylene and propylene. Two basic technologies used are: Ultra Selective Cracking (USC) for pyrolysis and cooling systems and Advanced Recovery System (ARS) for cold partial evaporation. Ethylene efficiency is different ( $75 \%$ for ethane to $28 \%$ for hydrogenated gasoline).

In Linde method ethylene and propylene is produced from ethane to naphta hydrocarbons by thermal cracking method. Ethylene efficiency is different for different feedstock. For gasoline, naphta, LPG and ethane is $25 \%, 35 \%, 45 \%$ and $83 \%$ in order. 
Finally, Technip method has been chosen for this research due to advantages such as; producing olefins with minimum amount of energy and environmental issues. The best feedstock for thermal cracking unit due to its high ethylene selectivity and is ethane. In addition, ethane pyrolysis is simple and cheaper than other hydrocarbon (Shokrollahi Yancheshmeh, Seifzadeh Haghighi et al. 2013).

Most of reactions that lead to converting ethane to ethylene happen in steam cracking furnace (Dar, Nanot et al. 2012). In this situation determining the rate of cracking and product composition is complicated. Primary dissociations produce atomic and free radical species. Olefins are formed from the atomic and free radical species. The rates of secondary reactions are very high and can be calculated from Arrhenius equation (1) (El'Terman, Stepukhovich et al. 1965).

$\mathrm{K}=\mathrm{A} \cdot e^{\frac{-E}{R T}}$

Where $\mathrm{E}$ is activation energy and $\mathrm{A}$ is integration constant commonly termed the frequency factor.

The main reactions taking place in the furnace are summarized in Table 1. These reactions were obtained from literature.

Finding the optimum temperature in cracking furnace that leads to maximum ethane conversion and yield is another challenge in modeling a cracking furnace. Optimum is maximum/minimum objective for a given objective subject to constraints. For the 
simulation purpose the ethane conversion $\left(\mathrm{X}_{\mathrm{C} 2 \mathrm{H} 6}\right)$ is the ration of carbon products produced to all carbon compositions even the unconverted ones, as shown in equation 2.

Selectivity of ethylene $\left(S_{C_{2} H_{4}}\right)$ is also defined in equation 3 which is the carbon species of desired product divided by all carbon products excluding unconverted feed. Yield $\left(Y_{C_{2} H_{4}}\right)$ is the carbon proportion of the feed which is converted to the desired product as shown in equation 4 (Dar, Nanot et al. 2012).

$$
\begin{aligned}
X_{C_{2} \mathrm{H}_{6}} & =\frac{2 C_{C_{2} \mathrm{H}_{4}}+2 C_{C_{2} \mathrm{H}_{2}}+C_{C_{H_{4}}}+C_{C O}+C_{\mathrm{CO}_{2}}}{2 C_{C_{2} \mathrm{H}_{6}}+2 C_{C_{2} \mathrm{H}_{4}}+2 C_{C_{2} \mathrm{H}_{2}}+C_{C_{4}}+C_{C O}+C_{\mathrm{CO}_{2}}} \\
S_{C_{2} \mathrm{H}_{4}} & =\frac{2 C_{C_{2} \mathrm{H}_{4}}}{2 C_{C_{2} \mathrm{H}_{4}}+2 C_{C_{2} \mathrm{H}_{2}}+C_{C \mathrm{H}_{4}}+C_{C O}+C_{C_{2}}} \\
Y_{C_{2} \mathrm{H}_{4}} & =S_{C_{2} \mathrm{H}_{4}} \times X_{C_{2} \mathrm{H}_{6}}
\end{aligned}
$$

In a typical ethylene plant, the process may face a problem that the automated process system is not able to handle; such a condition is called an abnormal situation. Upsets in the ethylene process that result in flaring are considered abnormal situations ( $\mathrm{Fu}$ and $\mathrm{Xu}$ 2013). 
Table 1 Summary of Some Main Reactions in Cracking Furnace

\begin{tabular}{|c|c|c|c|}
\hline Reactions & $\mathrm{E}(\mathrm{Kcal} / \mathrm{Kmol})$ & A (1/mole.s) & References \\
\hline$C_{2} H_{6} \leftrightarrow C_{2} H_{4}+H_{2}$ & 65210 & $4.65 \times 10^{13}$ & $\begin{array}{l}\text { (Froment, Van de Steene et al. 1976, } \\
\text { Sundaram and Froment 1977, Shokrollahi } \\
\text { Yancheshmeh, Seifzadeh Haghighi et al. } \\
\text { 2013, van Goethem, Barendregt et al. } \\
\text { 2013) }\end{array}$ \\
\hline $\mathrm{C}_{2} \mathrm{H}_{6}+\mathrm{C}_{2} \mathrm{H}_{4} \leftrightarrow \mathrm{C}_{3} \mathrm{H}_{6}+\mathrm{CH}_{4}$ & 60430 & $7.08 \times 10^{10}$ & $\begin{array}{c}\text { (Froment, Van de Steene et al. 1976, } \\
\text { Shokrollahi Yancheshmeh, Seifzadeh } \\
\text { Haghighi et al. 2013) }\end{array}$ \\
\hline $2 \mathrm{C}_{2} \mathrm{H}_{6} \rightarrow \mathrm{C}_{3} \mathrm{H}_{8}+\mathrm{CH}_{4}$ & 65250 & $3.85 \times 10^{11}$ & $\begin{array}{l}\text { (Froment, Van de Steene et al. } \\
\text { 1976, Sundaram and Froment 1977, } \\
\text { Shokrollahi Yancheshmeh, } \\
\text { Seifzadeh Haghighi et al. 2013) }\end{array}$ \\
\hline $\mathrm{C}_{2} \mathrm{H}_{6} \rightarrow \mathrm{C}_{2} \mathrm{H}_{5}+\mathrm{H}^{-}$ & 88.91 & $5 \times 10^{16}$ & (Dar, Nanot et al. 2012) \\
\hline $\mathrm{C}_{2} \mathrm{H}_{6} \rightarrow 2 \mathrm{CH}_{3}$ & 89000 & $10.9 \times 10^{16}$ & (Dar, Nanot et al. 2012) \\
\hline$C_{2} H_{\dot{3}}+C_{2} H_{\dot{3}} \leftrightarrow C_{4} H_{6}$ & 0 & $1.26 \times 10^{13}$ & (Holmen, Olsvik et al. 1995) \\
\hline $\mathrm{CH}_{3}+\mathrm{C}_{2} \mathrm{H}_{3} \rightarrow \mathrm{C}_{2} \mathrm{H}_{2}+\mathrm{CH}_{4}$ & 0 & $2 \times 10^{13}$ & $\begin{array}{l}\text { (Holmen, Olsvik et al. 1995, Dar, Nanot } \\
\text { et al. 2012, van Goethem, Barendregt et } \\
\text { al. 2013) }\end{array}$ \\
\hline $\mathrm{C}_{3} \mathrm{H}_{8} \rightarrow \mathrm{C}_{2} \mathrm{H}_{4}+\mathrm{CH}_{4}$ & 50600 & $4.69 \times 10^{10}$ & $\begin{array}{l}\text { (Froment, Van de Steene et al. 1976, } \\
\text { Sundaram and Froment 1977, Shokrollahi } \\
\text { Yancheshmeh, Seifzadeh Haghighi et al. } \\
\text { 2013) }\end{array}$ \\
\hline$C_{3} H_{8} \leftrightarrow C_{3} H_{6}+H_{2}$ & 51290 & $5.89 \times 10^{10}$ & $\begin{array}{l}\text { (Froment, Van de Steene et al. 1976, } \\
\text { Sundaram and Froment 1977, Shokrollahi } \\
\text { Yancheshmeh, Seifzadeh Haghighi et al. } \\
\text { 2013) }\end{array}$ \\
\hline $\mathrm{C}_{3} \mathrm{H}_{8}+\mathrm{C}_{2} \mathrm{H}_{4} \rightarrow \mathrm{C}_{2} \mathrm{H}_{6}+\mathrm{C}_{3} \mathrm{H}_{6}$ & 59060 & $2.53 \times 10^{13}$ & $\begin{array}{c}\text { (Froment, Van de Steene et al. 1976, } \\
\text { Sundaram and Froment 1977) }\end{array}$ \\
\hline
\end{tabular}


The literature has shown that GHG emissions are relatively high for the ethylene industry. A reported case showed that for a plant with a 600,000 tons/yr capacity can have flaring rate up to 2,500 tons/yr. At a flare efficiency of $98 \%$, the GHG emissions will contains approximately $15.4 \mathrm{MM}$ lbs of $\mathrm{CO}_{2}, 40,000 \mathrm{lbs} \mathrm{CO}, 7,400 \mathrm{lbs} \mathrm{NO}_{\mathrm{x}}, 15,100$ lbs hydrocarbons and 100,000 lbs highly reactive volatile organic compounds (HRVOC) (Liu and Xu 2010). The management of process upsets via flaring of process streams has obvious negative environmental consequence. In addition, such practices lead to lost opportunities for energy and mass recovery. One of the reasons for flaring is safety (Buzcu-Guven, Harriss et al. 2010). However, upset streams may be used in cogeneration units as fuel for producing heat and power together instead of burning as flares.

\section{Flare Streams}

\section{Definition and Causes}

Flaring is used to burn upset streams or toxic and combustible streams. In the petrochemical industry flaring is used to depressurize gas processing equipment in maintenance and emergencies. In gas processing plants, waste gases and gases burned throughout emergencies, equipment upsets and failures and maintenance operations are flared (Daniel A. Crowl 2011).

Flare streams in term of occurring could be categorized into two groups: (1) emission events which happen infrequently and separately in different time intervals, (2) continuous emissions which occur frequently in different operations (Jagannath, Hasan 
et al. 2012). There are two types of flare streams: continuous and process upset streams. In this research emission events (process upset flare streams) have been studied.

\section{Flare Environmental Impact}

Low efficiency flares and impurities in the fuel entering flare, discharges some hazardous by-products such as $\mathrm{CO}$, polycyclic aromatic hydrocarbons (PAH), carbon disulphide $\left(\mathrm{CS}_{2}\right)$, sulfur oxide $\left(\mathrm{SO}_{\mathrm{x}}\right)$, nitrogen oxides $\left(\mathrm{NO}_{\mathrm{X}}\right), \mathrm{CO}_{2}$, volatile organic compound (VOC) (Daniel A. Crowl 2011, Rahimpour and Jokar 2012). 75\% of emission of $\mathrm{CO}_{2}$ which is a greenhouse gas is a result of fossil fuel combustion. Therefore reduction of $\mathrm{CO}_{2}$ is an important issue (Rahimpour, Jamshidnejad et al. 2012).

\section{Causes for Flaring}

One of the reasons for flaring is safety. Flaring prevent release of high pressure gas in process malfunction and in emergency shutdowns. Furthermore, the gas may have a large amount of toxic materials such as hydrogen sulfide. Since removal of sulfur and other contaminants is not economical, the safest way to dispose of these acidic components is flaring the gas (Buzcu-Guven, Harriss et al. 2010).

"Off-spec" material is another reason for flaring. These materials are produced during process upset or after restarting a shutdown process. They cannot be stored or purified. However, there are ways to decrease flaring such as maximizing plant operations stability to prevent upset conditions which lead to flaring and also finding economical 
and practical solutions for storing, purifying and reusing material that should be flared (Patt and Banholzer 2009).

Flare Mitigation Methods

According to the environmental impact of gas flaring it is probable that in few years no flare will be allowed. No flare needs change in gas processing.

Plant upsets causing flare can be classified into two categories of off-spec streams: longtime upsets with large quantity (LTLQ) and short-time upsets with small quantities (STSQ). Flare minimization methods could be based on recognizing the off-spec streams, determining whether the stream is LTLQ or STSQ, deciding where to recycle. One method of flare minimization can be reducing the time of start-up by warming up the plant to an operating situation before the plant starts the process another method is recycling the off-spec products to their upstream process in this case for STSQ upset the first priority is recycling to CGC system inlet while for LTLQ upset is furnace system inlet.

Other mitigation/ recovery techniques are such as; electricity generation with a gas turbine and compression method or using multiple pump systems (Buzcu-Guven, Harriss et al. 2010, Rahimpour and Jokar 2012). In electricity generation method, the kinetic energy of a moving liquid or gas in a turbine will be transformed to mechanical energy. Burning gas turbines produce hot combustion gases which pass through a turbine and rotate turbine's blade and generate electricity. In compression method, the flare gas is 
compressed for reuse. A compressor increases the pressure of a compressible fluid. The configuration of compressor being used depends on its application (Rahimpour and Jokar 2012). Finally, recycling flare streams to a cogeneration system that can produce heat and power simultaneously to satisfy heat demands of ethylene plant is another option for reducing both GHG emission and natural gas usage.

\section{Case Study- Ethylene Process}

Start-up of ethylene plant produces a large amount of off-spec materials that should be sent to flaring (Liu and $\mathrm{Xu}$ 2010). Flaring happens for streams that are capable of producing more products in industry. In order to reduce flare emission in Ethylene plant, the process and flare sources should be recognized. As described before main flare happens due to start-ups, shut-downs, process upsets, and plant trips.

$\mathrm{Xu}$ et al. defined some major flaring streams in an ethylene process that will be shown in detail in chapter 3 , which are (Yang, Xu et al. 2010):

$\checkmark$ Feed to compressor: In plant start-ups or when the compressor is shut down but the cracked gas is still continue to flow, compressors are unable to accept cracked gas and subsequently it will be send to flare system.

$\checkmark$ Deethanizer overheads: When the top product will be more than the limit of acetylene hydrogenation reactor, the product will be flared.

$\checkmark$ Acetylene reactor outlets: The maximum flaring because of plant start-up and process up-set in ethylene plant happens in this place. If outlet streams that does not have proper quality for splitter unit it will be flared. 
Ethylene splitter upper outlets: because the final purity of product should be around 99.95 vol. \% otherwise the stream will be directed to flare system.

\section{Sweetening Process}

Natural gas is the most utilized fuel used in different area. Since it is found in deep reservoirs it may contain components such as hydrogen sulfide and carbon dioxide. These components due to their properties cause corrosion and are toxic therefore they should be separated from natural gas before natural gas will be applied in any other processes. Separation of $\mathrm{H}_{2} \mathrm{~S}$ and $\mathrm{CO}_{2}$ take place in sweetening unit (Amine process). Separation process is by bonding $\mathrm{H}_{2} \mathrm{~S}$ and $\mathrm{CO}_{2}$ with an amine component such as; monoethanolamine (MEA) and dimethylamine (DEA) (Abdulrahman and Sebastine 2013). For treatment of 25 MMSCFD of natural gas including $3 \mathrm{~mol} \% \mathrm{H}_{2} \mathrm{~S}$ and 4.13 mol $\% \mathrm{CO}_{2}$, total cost including capital and operating cost for 365 working days is about (\$5.75 million + \$2.95 million) \$8.7 million (Muhammad and GadelHak 2014).

\section{Claus Process}

Hydrogen sulfide is corrosive and highly toxic gas, which deactivates industrial catalysts. Natural gas contains hydrogen sulfide that should be removed. Separated Hydrogen sulfide is recovered in Claus process at every location that it is produced. Sulfur recovery is process of converting hydrogen sulfide as a by-product of natural gas plants to non-toxic element sulfur. One of the methods most used is the Claus process. This process produces almost $90 \%$ to $95 \%$ of recovered sulfur (Siemens 2007). Claus 
process was first invented 100 years ago and since then a lot of improvement has been done in the process. In earlier times, the plant was consisted of two catalytic stages. Then a thermal stage was added to the plant in the 1930s that causes an increase in efficiency from $95 \%$ to $97 \%$. In the 1970 s, a hydrogenation/ hydrolysis plus amine separation was also added for treating tail gas. In 1988, a selective oxidation reactor was added to the end of Claus process. The reactor increased efficiency to $99 \%$. The new Claus process was known as super Claus plant. The Claus reactions are highly exothermic and the heat energy released can be recovered by generating steam in heat exchangers following the conversion stages. Most Claus plants consist of two major conversion stages: one of them is thermal conversion stage and the other one is two or more catalytic conversion stages in series (Siemens 2007). Typical investment cost for Claus plant is around 8 million DM for a $200 \mathrm{t} / \mathrm{d}$ (Heisel and Marold 1987).

\section{Cogeneration}

Generating electrical and thermal energy simultaneously in a single integrated system is known as cogeneration. The combined efficiency of traditional method of generating power and heat separately is about $45 \%$ but in cogeneration systems the efficiency can reach $80 \%$ (EPA 2008).

Cogeneration unit require about $3 / 4$ of energy that heat and power system separately. This reduces fuel consumption and finally results in fewer emissions. Total cogeneration efficiency is defined as the ratio of net output to fuel consumed (CHP 2008). 
Some benefits of Cogeneration are described as below (UNEP 2006):

$\checkmark$ Reduction in emission of greenhouse gas to the environment

$\checkmark$ Increase in energy conversion efficiency

$\checkmark$ Flare gases are used as fuels for cogeneration unit, which increases the costeffectiveness and reduces the $\mathrm{CO}_{2}$ emission

$\checkmark$ Cost saving method, competing with industrial users while offering affordable energy

$\checkmark$ A new prospect to have more decentralized forms of electricity generation, where plants are designed to meet the needs of local consumers, providing high efficiency, avoiding transmission losses and increasing flexibility in system use. This will particularly be the case if natural gas is the energy carrier

A simple cogeneration unit which is shown in Fig. 1 is usually consists of a boiler, turbine, condenser tank, de-aerator and a pump. 


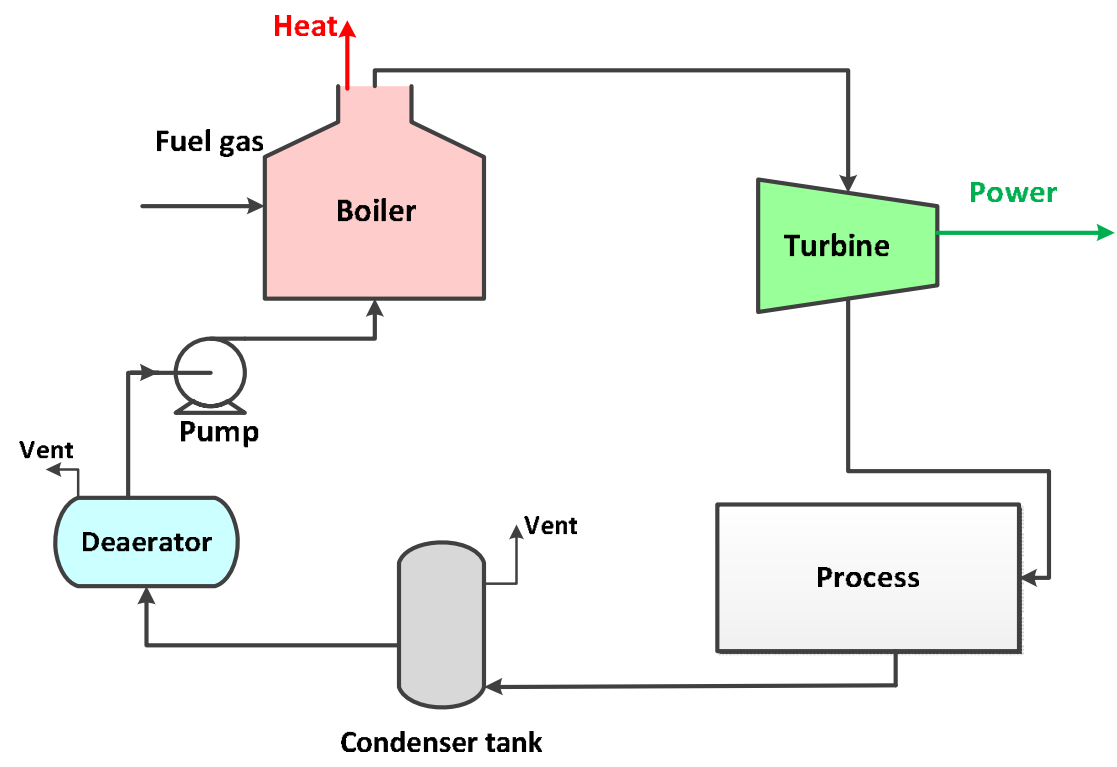

Figure 1 Cogeneration Unit

\section{Types of Cogeneration Systems}

There are different types of cogeneration systems. One classification could be based on the type of turbine used such as: steam turbine cogeneration system, gas turbine cogeneration system and reciprocating engine cogeneration system. Another classification is based on sequence of energy utilized: topping cycle and bottoming cycle.

\section{Topping Cycle}

The first object in this method is to produce power required and then heat required as a secondary object which is a by-product of the cycle (UNEP 2006). 


\section{Bottoming Cycle}

In this cycle the first aim is to generate heat required for the plant and then the heat rejected from the process is used to generate power. This cycle is appropriate for manufacturing processes that require heat at high temperatures (UNEP 2006).

Different type of turbines (which can be the type of cogeneration unit) and boiler can be utilized in a cogeneration system based on the requirements and applying fuels. Some common types of turbines are explained in the following section.

\section{Steam Turbine Cogeneration System}

This method is one of the oldest technologies still in general production. Steam turbines have high efficiencies and lower costs and they are widely used for combined heat and power generation. The capacity of a steam turbine can vary from $50 \mathrm{KW}$ to several hundred MW. The thermodynamic in steam turbine is Rankin cycle. This cycle is the basis for power generating units and boilers. Water is first pumped to medium to high pressure and then heated to boiling temperatures corresponding to the pressure and then most of the time steam is superheated and then a multistage turbine lower the pressure of steam and finally an intermediate steam distribution deliver steam to industrial application. Two types of steam turbine widely used are the backpressure and the extraction-condensing turbine. Choosing between these two types of turbine depends on quality of heat, quantity of power and heat and other economic factors (UNEP 2006). 


\section{Gas Turbine Cogeneration System}

This system is based on Brayton cycle. Gas turbine systems generate all or a part of the energy required for the plant, and the energy released at high temperature in the exhaust stack is applied for various heating and cooling applications. While natural gas is most used in cogeneration system, other fuels such as light fuel oil or diesel can also be employed. The typical range of gas turbines varies from a fraction of a MW to around 100 MW. Some of gas turbine advantages are: reduced installation costs, better environmental performance, more availability of natural gas, having short start up time. If the heat output is less than that required heat, supplementary natural gas can fired by mixing additional fuel to the oxygen-rich exhaust gas to improve the heat output more efficiently (UNEP 2006).

\section{Reciprocating Engine Cogeneration System}

Some advantages of Reciprocating engines are quick start up, having good part- load efficiencies, high reliability, sometimes increasing overall plant capacity and availability. Reciprocating engines have higher electrical efficiencies compared to gas turbines of comparable size, and therefore lower fuel-related operating costs. In addition, the first costs of reciprocating engine are generally lower than gas turbine up to 3-5 MW in size. However, Reciprocating engine maintenance costs are usually higher than comparable gas turbines. One solution to this problem is that the maintenance can often be handled by in-house staff or by local service organizations (UNEP 2006). 
De-aerator is also one of the units in cogeneration system. Since dissolved gases such as oxygen and carbon dioxide can cause corrosion, deaerator unit is responsible for separating them from condensate stream to steam generating boiler (Jiang X. 2013).

\section{Wobbe Index}

Due to change in composition of fuel sent to the burners, there is a need to make sure that fuels quality meets the needs. Wobbe index (WI) or wobbe number represents the heating value of the fuel, which means that gases that have the same WI will produce the same amount of heat. WI is defined as in BTU per standard cubic foot divided by the square root of the specific gravity, shown in equation 5 (Jagannath, Hasan et al. 2012).

$\mathrm{WI}=\frac{\text { Lower heating value }}{\sqrt{\text { Specific gravity }}}$

Therefore, 'the higher the WI, the greater the heating value of the quantity of gas that will flow through a hole of a given size in a given amount of time'. Flow of a gas is usually regulated by passing it through an orifice. Equipment operates in a specific range of WI. Natural gas has a wobbe number between 1310 and 1390 (Jagannath, Hasan et al. 2012).

One way to make sure that the fuel sent to burner is proper for the equipment and also satisfy heating requirements is to control the WI. In some cases natural gas is mixed with the fuel to change their WI and make it between highest and lowest range of natural gas WI. 
Some important reasons for identifying the WI of the fuel used are (Blomstedt et al.):

$\checkmark$ Specific amount of heat is needed for start-up of unit, otherwise start-up run will fail.

$\checkmark$ Every design has a high and low range of WI which determines which fuels are acceptable.

Issues that may happen when a fuel with properties close to limits of a design is chosen are (Blomstedt et al.):

$\checkmark$ Flash back (fuel ignites immediately and flame gets closer to burner tip)

$\checkmark$ Pulsation (ratio of air and fuel is not proper and may cause cracking of components)

$\checkmark$ Flame out (too lean mixture of fuel and air cause flame out and explosion in downstream)

$\checkmark$ Emission (combustion efficiency decrease and emissions of $\mathrm{NO}_{\mathrm{x}}$ and $\mathrm{CO}_{\mathrm{x}}$ will increase). 


\title{
CHAPTER III
}

\section{ETHYLENE, SWEETENING AND CLAUS PROCESS MODELING*}

\author{
Problem Statement
}

Consider a process with a known historical record of flaring that includes the causes of flaring, the duration and frequency of each flaring event, and the quantity and composition of the flared gases. It is desired to develop a process retrofitting approach to install a cogeneration system that uses the flared gas to produce heat which is used for steam generation and, subsequently, for combined heat and power. The process heating and cooling demands are known and are to be integrated with the thermal loading of the cogeneration system. The metrics guiding the design should include fixed and operating costs of retrofitting, economic benefits resulting from the effective utilization of the flared gases, the values of the produced heat and power, and the reduction in GHG emissions.

\section{Approach}

The proposed approach is shown by Fig. 2. First, the process steady-state base case study is modeled using a combination of published data and computer-aided simulation tools. Additionally, the dynamic data for the abnormal situations are provided in the form of flaring events. Each event is characterized by frequency, duration, flared amounts, and

\footnotetext{
"Part of this chapter is reprinted with permission from "Managing abnormal operation through process integration and cogeneration systems" by Serveh Kamrava, Kerron J. Gabriel, Mahmoud M. ElHalwagi, Fadwa T. Eljack, 2014. Clean Technologies and Environmental Policy, pg. 1-10, Copyright [2014] by Springer Science+ Business Media"
} 
composition of the flared gases. Next, process data are extracted as: (i) heating, cooling, and power demands and (ii) flaring events data. The heating and cooling data are processed through a heat-integration model to minimize the use of external heating and cooling utilities and to determine the thermal profile of the process consistent with the identified utility targets. The flare gases are considered for cogeneration by extracting the heating value via combustion, converting the heat into steam, and letting down the steam through turbines to produce power and to utilize the exiting steam for process heating. A simple cogeneration diagram is shown in Fig. 1. The heating requirements of the process dictate the throughput and steam outlet specifications of the cogeneration unit. In addition, the design philosophy of the cogeneration unit would have both GHG emission and economic impacts. To assess these factors a cogeneration model was developed to evaluate the GHG emissions via combustion of selected boiler fuels and macroscopic reduction via simultaneous power production. The IAPWS-97 (The International Association for the Properties of Water and Steam 1997) industrial formulation for the thermodynamic properties of water and steam were used to develop and evaluate the performance of the cogeneration process. Modeling and optimization approaches of cogeneration systems were used (Al-Azri, Al-Thubaiti et al. 2009, ElHalwagi, Harell et al. 2009, Bamufleh, Ponce-Ortega et al. 2013). Economic data from literature (Peters, Timmerhaus et al. 2002, El-Halwagi 2012) were used to estimate the economic implications of each desired cogeneration design. The model was extended to quantify the reduction of GHG emissions due to the use of flare gases as a fuel source 
thus avoiding or decreasing flaring. The economic and environmental data are used to run various scenarios and to establish cost-benefit analyses.

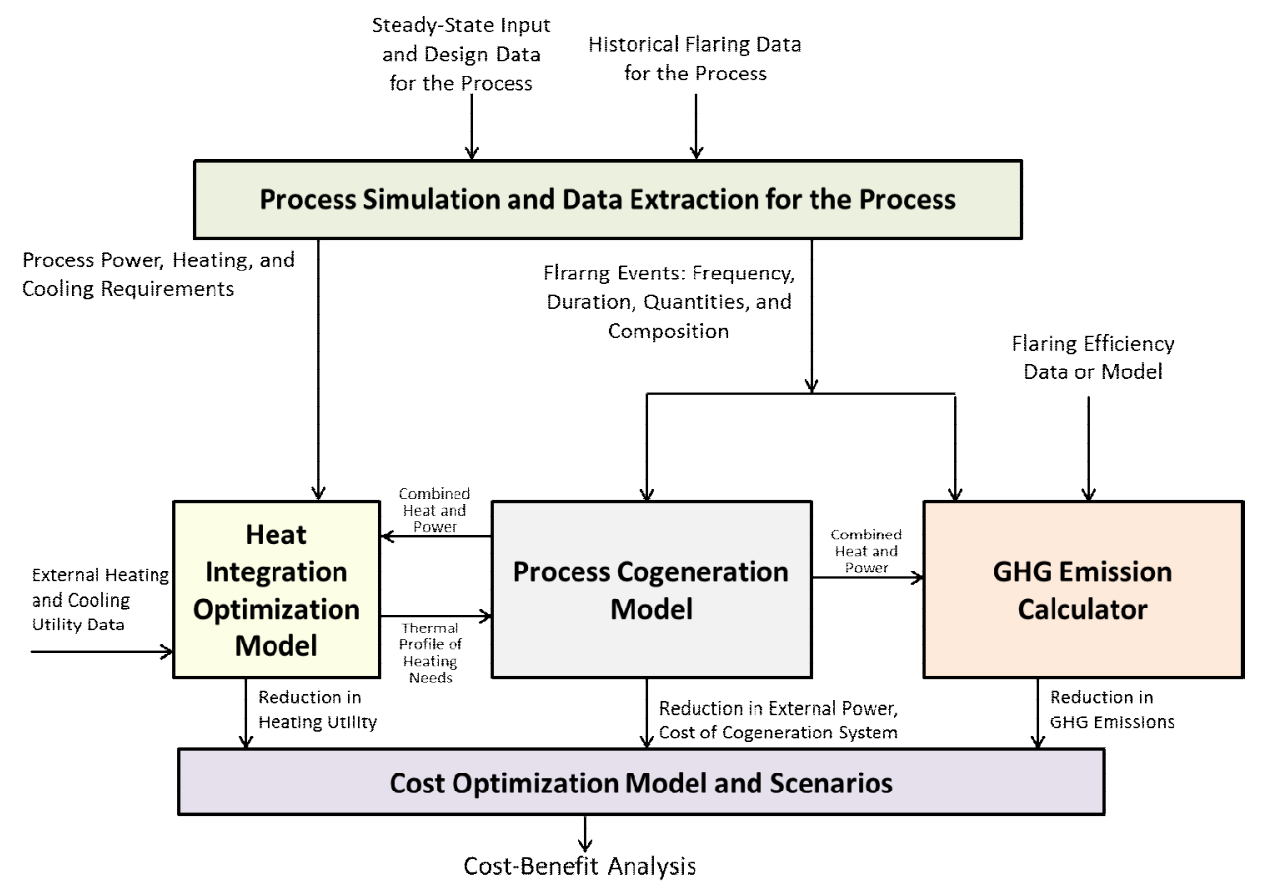

Figure 2 Approach to Manage Flares through Cogeneration

To demonstrate the usefulness of the proposed approach, a case study on ethylene production is used and presented below.

\section{Case Study}

The basis for the ethylene process study is that 900,000 tons/yr of ethylene is produced and the feed contains 96 wt. $\%$ of ethane, 3 wt. $\% \mathrm{H}_{2} \mathrm{~S}$, and 1 wt. $\%$ of $\mathrm{CO}_{2}$. Steam to gas ratio in cracking furnace is 1 to 3 . The experimental data from Dar, Nano et al. 
experiments are as shown in the Table 2. The experimental data is based on converting $100 \mathrm{lbs}$ ethane to ethylene at different temperature which results in different conversion and yield. As seen in Figure 3 the ethylene selectivity and ethane conversion has the optimum amount at $1700{ }^{0} \mathrm{~F}$. Therefore the furnace outcome stream at $1700.33{ }^{0} \mathrm{~F}$ with $87.6 \%$ conversion has been scaled up to have 900,000 tons/yr of ethylene.

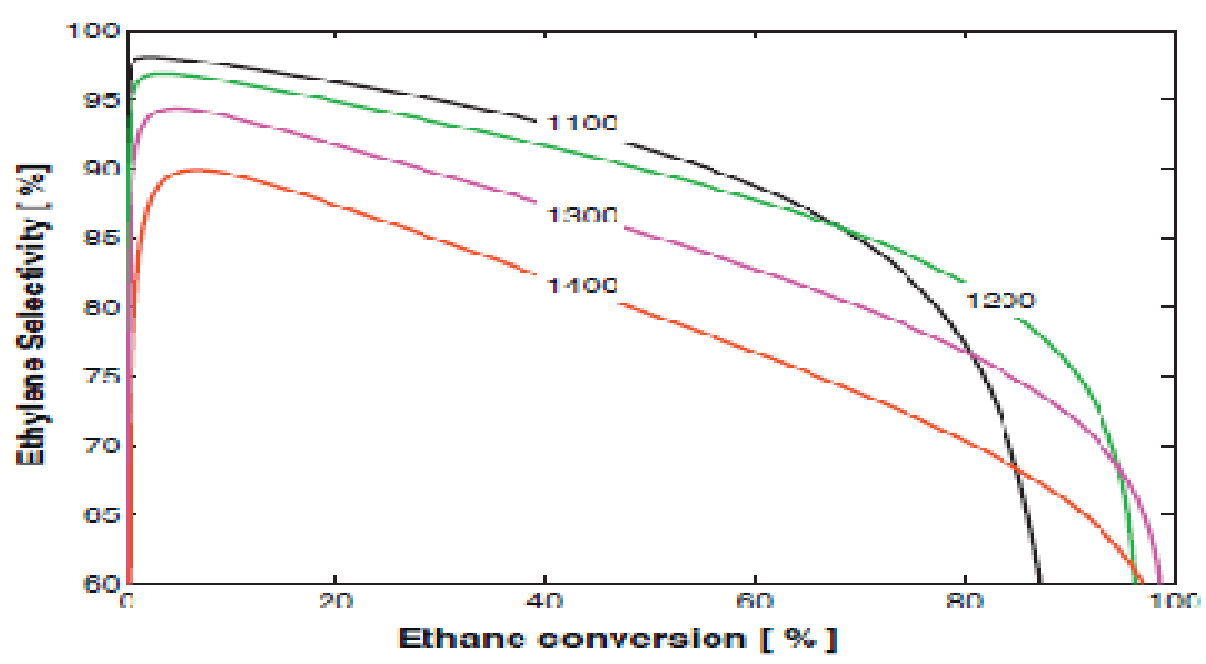

Figure 3 Selectivity of Ethylene versus Ethane Conversion (Dar, Nanot et al. 2012)

Finally the temperature of $1700.33{ }^{0} \mathrm{~F}$ is chosen as the optimum point for having maximum conversion and yield. At $1700.33{ }^{0} \mathrm{~F}$, ethane conversion and yield is $87.6 \%$, $67.1 \%$ respectively. Acetylene rector conversion is assumed to be $100 \%$. 
Table 2 Results of Ethane Pyrolysis in Uniform Temperature (Dar, Nanot et al. 2012)

\begin{tabular}{|c|c|c|c|c|}
\hline $\mathrm{T}\left({ }^{0} \mathrm{~K}\right)$ & 1100 & 1200 & 1300 & 1400 \\
\hline Time (ms) & 800 & 92 & 12 & 1.6 \\
\hline Conversion & 75.6 & 87.6 & 91.2 & 88.3 \\
\hline Components & \multicolumn{4}{|c|}{ Wt.\% } \\
\hline $\mathrm{H}_{2}$ & 4.5 & 5.1 & 5.2 & 5 \\
\hline $\mathrm{CH}_{4}$ & 6.4 & 8.6 & 10.5 & 10.9 \\
\hline $\mathrm{C}_{2} \mathrm{H}_{2}$ & 0.2 & 1.1 & 2.4 & 3.1 \\
\hline $\mathrm{C}_{2} \mathrm{H}_{4}$ & 59.2 & 67.1 & 67.4 & 64.2 \\
\hline $\mathrm{C}_{2} \mathrm{H}_{6}$ & 24.3 & 12.4 & 8.8 & 11.7 \\
\hline $\mathrm{C}_{3} \mathrm{H}_{4}$ & 0.1 & 0.1 & 0.1 & 0.2 \\
\hline $\mathrm{C}_{3} \mathrm{H}_{6}$ & 1.4 & 1.1 & 0.9 & 1.1 \\
\hline $\mathrm{C}_{4} \mathrm{H}_{4}$ & 0.1 & 0.3 & 0.8 & 0.8 \\
\hline Butadiene & 0.7 & 1.5 & 1.8 & 1.6 \\
\hline Cyclopentadiene & 0.4 & 0.5 & 0.3 & 0.2 \\
\hline Benzene & 1.1 & 1.2 & 1 & 0.5 \\
\hline Styrene & 0.2 & 0.2 & 0.1 & 0.1 \\
\hline Naphthalene & 0.4 & 0.2 & 0.1 & 0 \\
\hline
\end{tabular}

A typical ethylene process includes a sweetening unit for separation of hydrogen sulfide and a Claus process to convert separated hydrogen sulfide to non-toxic sulfur element. The sections below provide more details. First, the pretreatment system is described, and then the ethylene process is presented. 


\section{Gas Pre-Treatment}

\section{Sweetening Process}

Sour gases should be separated completely from the gas stream before entering the cracking furnace. The removal of $\mathrm{H}_{2} \mathrm{~S}$ and $\mathrm{CO}_{2}$ takes place in sweetening section of the process as shown in Fig.4. The sweetening unit is an endothermic process, in which sour feed is first contacted with 22 wt.\% of mono-ethanolamine (MEA) in an absorber unit and consequently amine will bond with $\mathrm{H}_{2} \mathrm{~S}$ and $\mathrm{CO}_{2}$. The residue gas which now has trace amounts of $\mathrm{CO}_{2}$ and $\mathrm{H}_{2} \mathrm{~S}$ leaves from the top of absorber and the rich amine stream that now has high concentrations of $\mathrm{CO}_{2}$ and $\mathrm{H}_{2} \mathrm{~S}$ will go to flash drum. Some of lighter components will separate as flash gas. Rich amine stream is then sent to the stripper for regeneration. Lean amine leaving stripper column will be recycled and then make up amine is added to this stream based on inlet concentration of $\mathrm{H}_{2} \mathrm{~S}$. Outlet $\mathrm{H}_{2} \mathrm{~S}$ concentration of sweetening unit (MEA unit) is decreased to $18 \mathrm{ppm}$. If sweetening unit fails for any reason, the stream which has $\mathrm{H}_{2} \mathrm{~S}$ will not be sent to ethylene plant or cogeneration. These streams will be sent to a special design of flares. The reason for using special flare stacks is that regular designed flare will produce $\mathrm{SO}_{2}$ and $\mathrm{SO}_{3}$ by burning these streams which cause acid rain. This amount will be reduced to zero in an absorber column with zinc oxide as shown in the main ethylene process. Heat demand for the sweetening unit depends on the amine flow rate used for separating hydrogen sulfide to the required amount. In other words, the energy required for sweetening unit is used to break the bond between hydrogen sulfide and amine in stripper column. 
Properties that should be determined for simulation of sweetening unit are: feed stream, $\mathrm{H}_{2} \mathrm{~S}$ concentration outlet stream (Residue gas), make up concentration (gpm).

We determined the flow rate of feed to the sweetening unit (dry basis sour feed) based on the flow rate going into cracking unit to have the final ethylene production. The composition of the dry basis sour feed is as described in Table 3.

Table 3 Inlet Feed Stream Properties to Sweetening Unit

\begin{tabular}{|c|c|c|c|c|}
\hline Dry basis sour feed & Wt. $\%$ & $\mathrm{M}_{\mathrm{W}}$ & $1 b_{\text {mole }}$ & Mole $\%$ \\
\hline Ethane & 96 & 30 & 3.2 & 96.65 \\
\hline $\mathrm{H}_{2} \mathrm{~S}$ & 3 & 34 & 0.0882 & 2.66 \\
\hline $\mathrm{CO}_{2}$ & 1 & 44 & 0.02213 & 0.69 \\
\hline
\end{tabular}

Standard for $\mathrm{H}_{2} \mathrm{~S}$ concentration in natural gas pipelines is 1 grain/100 cuftgas. Based on the assumption that ethane flow rate coming out of MEA unit is $\mathrm{F}$ (lbmole/hr), and then some of the calculations are as it is shown here.

Flow of ethane $=\mathrm{F}($ lbmole $/ \mathrm{hr}) \times 379.5(\mathrm{scf} / \mathrm{lbmole})=379.5 \times \mathrm{F}(\mathrm{scf} / \mathrm{hr})$

$\mathrm{H}_{2} \mathrm{~S}$ flow $=379.5 \times \mathrm{F}(\mathrm{scf} / \mathrm{hr}) \times(1$ grain $/ 100 \mathrm{scf}$ gas $) \times(1 \mathrm{lb} / 7000$ grain $)=54 . \times F \times 10^{-5}(\mathrm{lb} / \mathrm{hr})$

$\mathrm{H}_{2} \mathrm{~S}$ concentration in the acid gas $=\frac{54.21 \times F \times 10^{-5}\left(\frac{l b}{h r}\right)}{30 \times F\left(\frac{l b}{h r}\right)} \times 10^{6}=18 \mathrm{ppm}$ 
Finally this amount will be reduced to zero in an absorber column with zinc oxide before entering cracking furnace in ethylene process.

Next step is calculating Make up stream flow rate (GPM of MEA) using equation (6) assuming that MEA concentration of $22 \mathrm{wt} . \%$ is utilized.

$\mathrm{GPM}=\frac{41 \times Q \times y}{x}$

Where, $\mathrm{Q}$ is volume flow rate (MMscfd), $\mathrm{y}$ is Total mole of acid gas (\%), $\mathrm{x}$ is MEA concentration (\%).

Total mole $\%$ of acid gas $=2.66+0.69=3.35 \mathrm{~mol} \%$

Required Ethane (Stream2 Fig.6) = 10,583.6 (lbmole/hr)

Total molar flow $=\frac{10,583.6\left(\frac{l \mathrm{bmole}}{\mathrm{hr}}\right)}{96.65 \mathrm{~mol} \%}=10,950.44(\mathrm{lbmole} / \mathrm{hr})$

Volume flow $=10,950.44($ lbmole $/ \mathrm{hr}) \times 379.5(\mathrm{scf} / \mathrm{lbmole}) \times 24(\mathrm{hr} / \mathrm{day})=99.737 \mathrm{MMscfd}$

Make-up flow rate $=\frac{41 \times 99.737 \times 3.35}{22}=622.68 \mathrm{gpm}$

Heat demand for sweetening unit depends on amine flow rate used for separating hydrogen sulfide to the required amount. In other words, the energy required for sweetening unit is used to break the bound between hydrogen sulfide and amine in stripper column. 


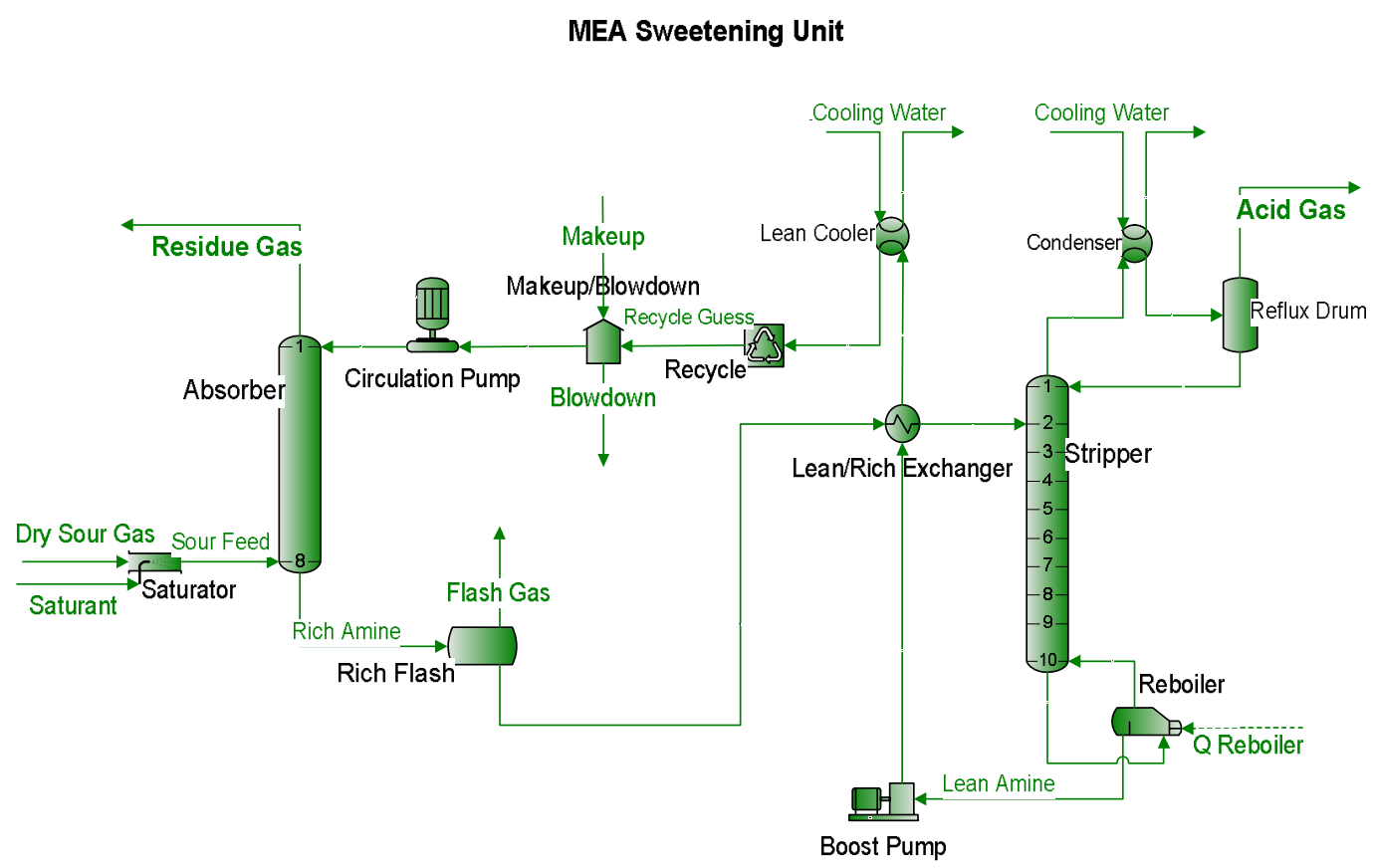

Figure 4 Sweetening Unit

\section{Claus Process}

A Claus plant is used after the sweetening unit to convert hydrogen sulfide to elemental sulfur because of toxicity of hydrogen sulfide that can deactivates industrial catalysts. Claus reactions are highly exothermic. The efficiency of this unit could be up to $99 \%$. The heat energy released can be recovered and used in other units such as sweetening unit. Only high temperature heat streams are usable which are shown in Table 4. The acid gas outlet stream of the sweetening unit is an inlet stream to the Claus plant.

The properties of inlet streams are described in Table 5. A case depicting Claus plant is shown in Fig.5. 
Simple Two Bed Claus Plant

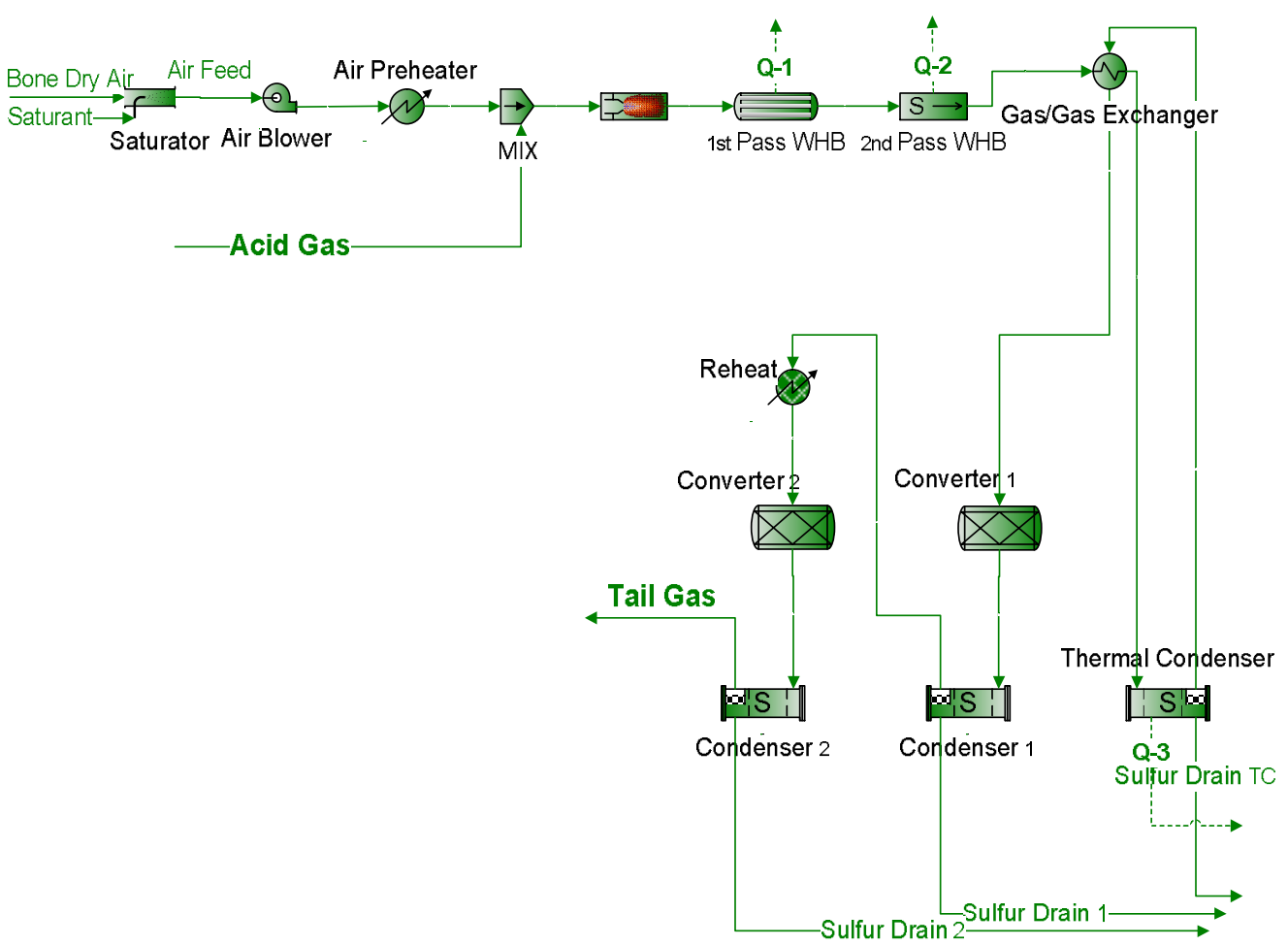

Figure 5 Claus Plant

Table 4 Claus Process Heat Streams

\begin{tabular}{|l|c|c|c|}
\hline \multirow{3}{*}{ Energy generated } & Energy Stream & Energy Rate (Btu/hr) & Temperature ( $\left.{ }^{0} \mathrm{~F}\right)$ \\
\cline { 2 - 4 } & Q-1 & $5.16759 \mathrm{E}+06$ & 1200 \\
\cline { 2 - 4 } & Q-2 & $6.80587 \mathrm{E}+06$ & 700 \\
\cline { 2 - 4 } & Q-3 & $2.28508 \mathrm{E}+06$ & 540 \\
\hline
\end{tabular}


Table 5 Properties of Inlet Stream of Claus Process

\begin{tabular}{|l|c|}
\hline components & Acid gas mole fraction (\%) \\
\hline Ethane & 0.6069 \\
\hline $\mathrm{CO}_{2}$ & 18.853 \\
\hline $\mathrm{H}_{2} \mathrm{~S}$ & 73.580 \\
\hline $\mathrm{MEA}$ & $4.05 \mathrm{E}-011$ \\
\hline $\mathrm{H}_{2} \mathrm{O}$ & 6.959 \\
\hline Mass flow (lb/hr) & 13795.5 \\
\hline Temperature $\left({ }^{0} \mathrm{~F}\right)$ & 120 \\
\hline Pressure (psia) & 26.7 \\
\hline
\end{tabular}

\section{Ethylene Process}

The base case study of ethylene process flow sheet is shown in Fig.6. The sweet ethane gas is fed to the cracking furnace. The furnace is operated at $1700.33{ }^{0} \mathrm{~F}$. The cracked gas is then quenched.

Light gases $\left(\mathrm{C}_{4+}\right)$ mixture is separated and sent to a three stage compressor section. The gas stream is further treated in $\mathrm{CO}_{2}$ removal unit to separate trace $\mathrm{CO}_{2}$ and then sent to the drying unit for removal of any moisture. Next is the ethylene separation sequence. This process is modeled using front-end de-ethanizer unit. There, the ethane and lighter gas mixture are recovered then sent to the $4^{\text {th }}$ stage compressor and the heavier mixture is sent for further separation. After the $4^{\text {th }}$ stage compression, the light gases enter the acetylene hydrogenation unit, where acetylene is totally converted to ethylene. The methane is then recovered in the de-methanizer unit. The bottom of the de-methanizer 
now contains mostly ethane and ethylene will be directed to the ethylene splitter unit to separate product and recycle ethane to feed stream.

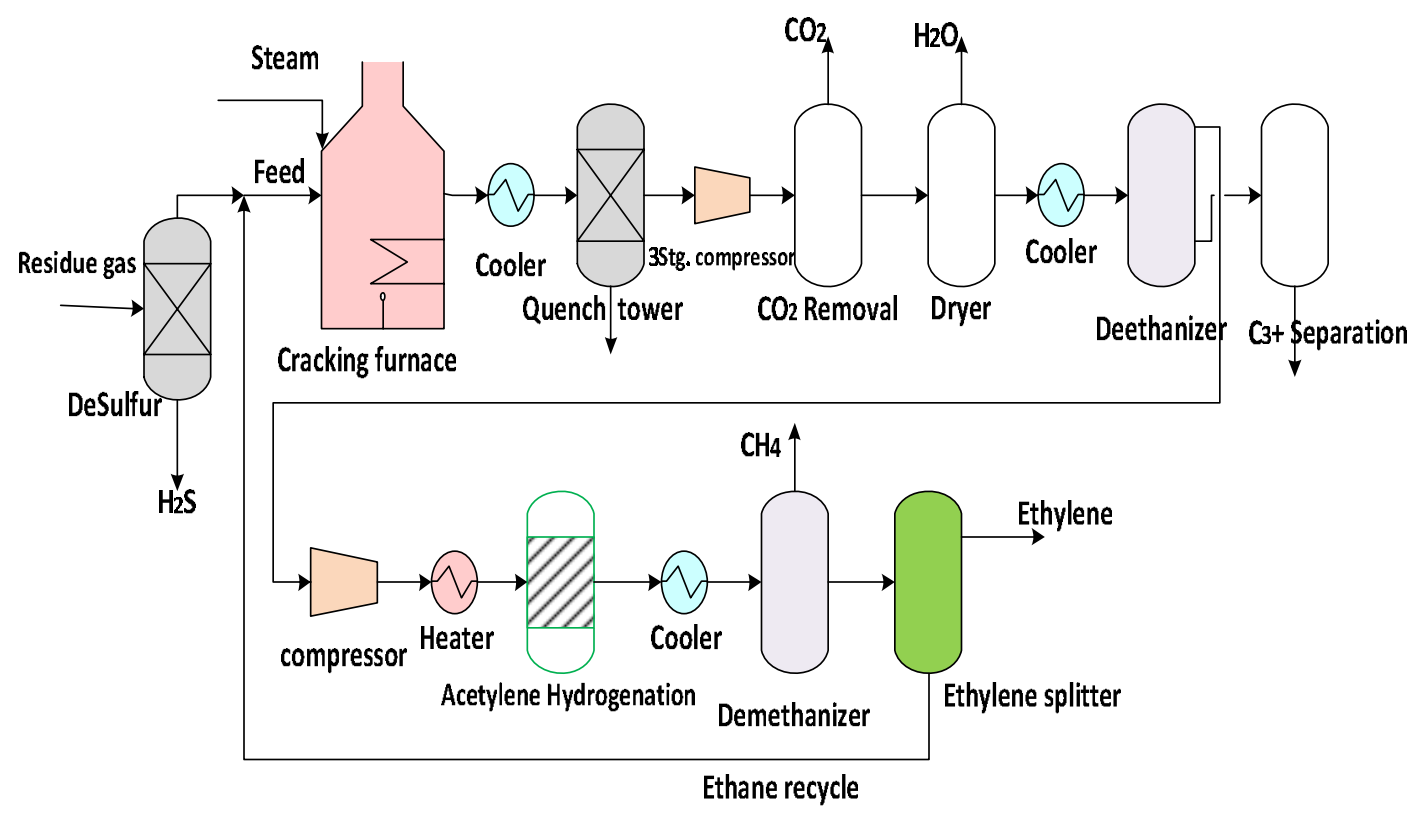

Figure 6 Ethylene Plant

\section{Ethylene Flares}

The proposed framework in this study is to integrate flare streams into a co-generation system. They are the stream feed to the $4^{\text {th }}$ stage compressor, the acetylene reactor outlet and the ethylene product stream as shown in Fig. 7. These potential flare sources have a high frequency of occurrence. Process flares due to upset are non-continuous and for calculation purposes the assumed flaring rates are on an annual basis. The operation situation that results in a flaring incident is referred to here as the flaring cause. The 
management of the upset results in flaring of one or more streams. That is here termed the consequence. Table 6 summarizes the cause and duration associated with each of the three flared streams used in this case study. We also assumed that total operational hour is $8000 \mathrm{hr} / \mathrm{yr}$ (Liu and $\mathrm{Xu}$ 2010, Yang, Xu et al. 2010). Here the basic assumption is the co-gen unit has a certain power and heat output.

Table 6 Different Flare Causes and Duration

\begin{tabular}{|l|c|c|}
\hline Streams & Causes & Duration (hr/yr) \\
\hline Flare A & Inlet stream to acetylene hydrogenation reactor is more than its limit & 12 \\
\hline Flare B & When outlet stream does not have proper quality for splitter unit & 12 \\
\hline Flare C & When final purity of product is not close to 99.95 vol.\% & 12 \\
\hline
\end{tabular}




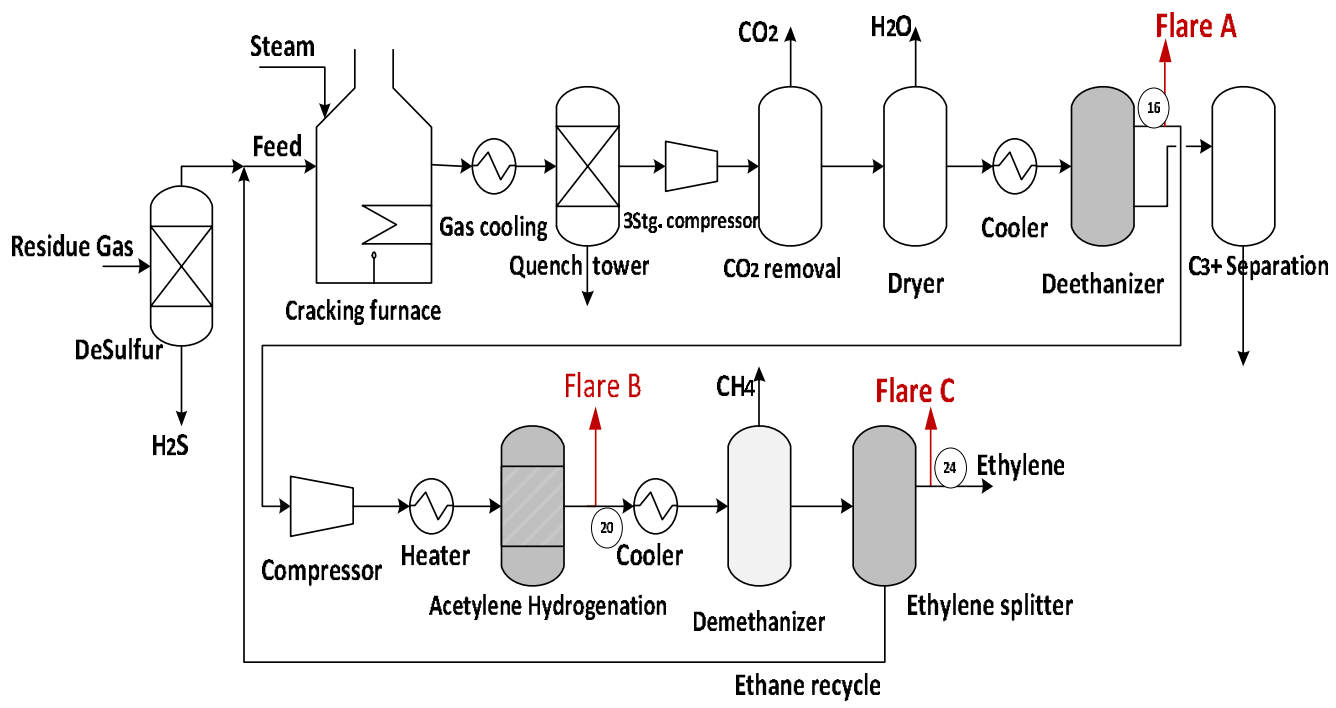

Figure 7 Flare Sources

\section{Cogeneration Unit}

In this section, we present the case of mitigating process upsets via design of a cogeneration unit. The streams that would be traditionally sent to flare are proposed to be re-directed and fed to the standby co-generation system. The amount of energy recovered and power generated as a result are being estimated for each of the flaring streams with two scenarios.

Cogeneration systems are described earlier in the introduction and literature review in chapter II. For the case study a simple steam turbine cogeneration unit is considered, see Fig.1. Flare streams are fed to the boiler in cogeneration unit. Based on heat demand of process, the steam flow rate is determined. Water will be heated in the boiler to superheated temperature. Subsequently, the steam from boiler in cogeneration unit is 
sent to the process to satisfy heating demands in the process. The additional steam will flow to an isentropic turbine to produce electricity. Steam that has been used in the process will lose pressure and temperature as a result. Therefore, a pump is placed to increase the pressure of this stream to the boiler conditions. Turbine and boiler are assumed to have efficiency of $75 \%$.

The heating output requirement of the cogeneration unit is determined as the net heating requirements in ethylene plant and in gas sweetening unit minus the amount that is produced in Claus plant as described in following line.

$\mathrm{Q}_{\text {produced_Cogeneration }}+\mathrm{Q}_{\text {produced_claus process }}=\mathrm{Q}_{\text {required_Boilers }}+\mathrm{Q}_{\text {required_sweetening unit }}$

For the case study here, the estimated cogeneration heating output calculated using the above equation is $36.8 \mathrm{MMBtu} / \mathrm{hr}$ of high pressure steam (50 psia). Generally the amount of power and heat generated by cogeneration system are quantified based on heating demand as a primary objective, or with power demand as a primary objective. In this case study, the co-gen unit is requested to satisfy the heat demand of ethylene plant as the primary objective and the power output would be the secondary objective.

The work presented here shows the potential in using stand-by cogeneration system to mitigate process upset. Future work will further investigate the design and operation of this cogeneration system with discontinuous flare streams.

In this research, first scenario is applied to determine amount of steam produced based on heating demand of the process. In our study, for heating demand of $36.8 \mathrm{MMBtu} / \mathrm{hr}$ 
in the ethylene process steam with pressure of 50 psia is needed. Natural gas or/and flare streams are used as feedstock to the boiler. Based on heat demand of process, the steam flow rate is determined. Water will be heated in the boiler to superheated temperature. Then it will flow to an isentropic turbine to produce electricity. Finally, generated heat and power is sent to the process. Steam will lose pressure as a result. Hence, a pump is placed to increase the pressure of the stream up to boiler feed conditions. Turbine and boiler are assumed to have efficiency of $75 \%$ and $80 \%$, respectively.

\section{Heat Integration}

\section{Ethylene Plant}

Saving energy through heat integration has drawn a lot of attention. In a plant there are units that require heating and also units that require cooling. Heat integration is based on transferring heat from hot streams to cold streams, instead of using external utilities for satisfying a part of heating and cooling demands (El-Halwagi 2012). First step is identifying streams that need heating and cooling, temperature change and heating duty. There are three hot streams $\left(\mathrm{H}_{1}, \mathrm{H}_{2}\right.$ and $\left.\mathrm{H}_{3}\right)$ that need cooling. Cold stream $\mathrm{C}_{1}$ is stream going to heater. Hot and cold stream data are presented in Table 7 and 8. First step of heat integration is constructing temperature interval diagram (TID) (Fig. 8). A minimum heat exchange driving force of $\Delta \mathrm{T}^{\mathrm{min}}=10^{0} \mathrm{~F}$ is assumed. Two columns in this figure represent hot and cold streams. Streams are specified as arrows pointing the target temperature. Amount of heat is calculated from equation 7. 
Table 7 Hot-Stream Data

\begin{tabular}{|c|c|c|c|c|}
\hline Stream & $\begin{array}{c}\text { Supply temperature } \\
\left({ }^{0} \mathrm{~F}\right)\end{array}$ & $\begin{array}{c}\text { Target temperature } \\
\left({ }^{0} \mathrm{~F}\right)\end{array}$ & $\mathrm{Q}(\mathrm{KW})$ & $\begin{array}{c}\text { Flow Ratex Specific Heat } \\
\left(\mathrm{KW} /{ }^{0} \mathrm{~F}\right)\end{array}$ \\
\hline $\mathrm{H}_{1}$ & 1700.33 & 173.0714 & -166741.39 & 109.17692 \\
\hline $\mathrm{H}_{2}$ & 110.5366 & 78 & -2028.3257 & 62.339817 \\
\hline $\mathrm{H}_{3}$ & 85.09944 & -110 & -23841.557 & 122.202078 \\
\hline
\end{tabular}

Table 8 Cold-Stream Data

\begin{tabular}{|c|c|c|c|c|}
\hline Stream & $\begin{array}{c}\text { Supply temperature } \\
\left({ }^{0} \mathrm{~F}\right)\end{array}$ & $\begin{array}{c}\text { Target temperature } \\
\left({ }^{0} \mathrm{~F}\right)\end{array}$ & $\mathrm{Q}(\mathrm{KW})$ & $\begin{array}{c}\text { Flow Ratex Specific Heat } \\
\left(\mathrm{KW} /{ }^{0} \mathrm{~F}\right)\end{array}$ \\
\hline $\mathrm{C}_{1}$ & -10.53017 & 125.33 & 8127.25 & 59.820732 \\
\hline
\end{tabular}

By applying the information of Table 7 and 8 , Temperature interval diagram is developed as shown in Fig. 8. Next step is developing table of exchange heat load (TEHL) for both hot and cold streams (Table 9 and 10). 


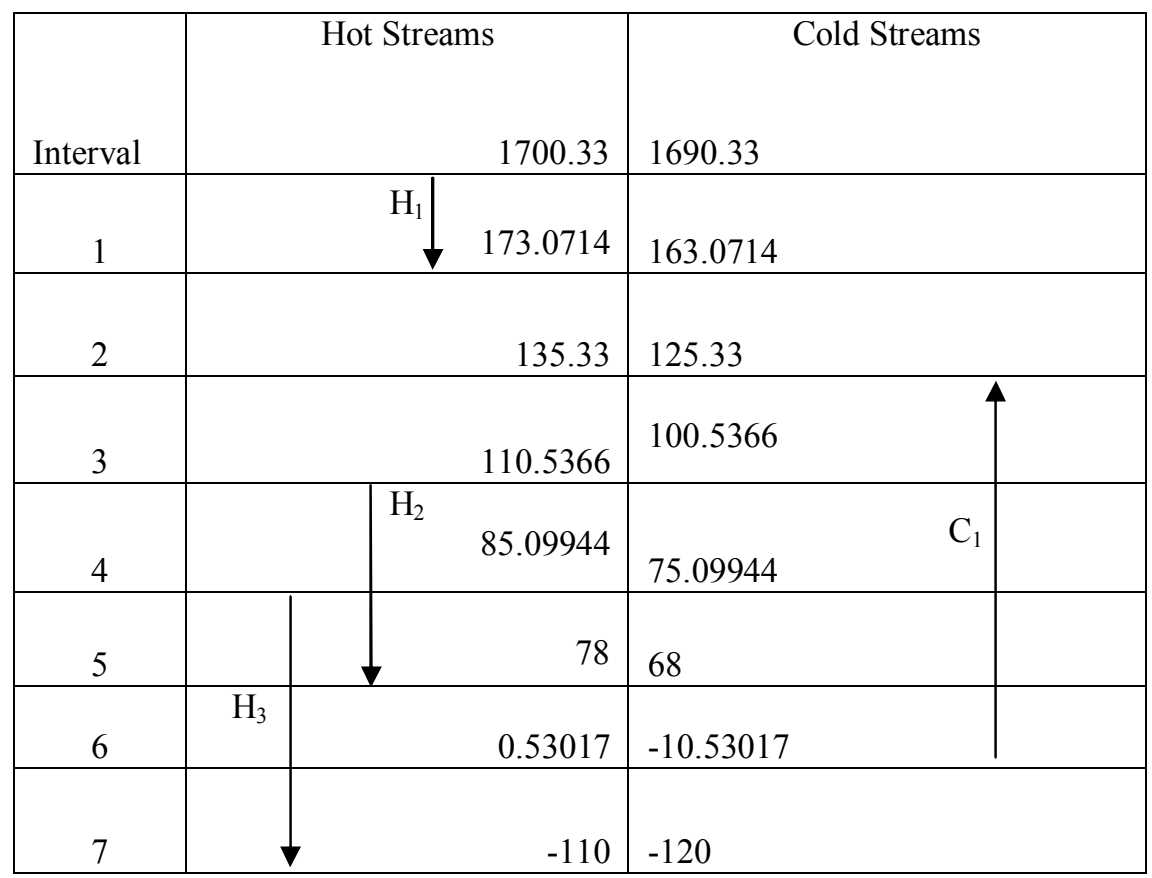

Figure 8 Temperature Interval Diagram for Ethylene Plant Case Study

Table 9 TEHL for Hot Streams in Ethylene Plant

\begin{tabular}{|l|c|c|c|c|}
\hline Interval & Load of $\mathrm{H}_{1}(\mathrm{~kW})$ & Load of $\mathrm{H}_{2}(\mathrm{~kW})$ & Load of $\mathrm{H}_{3}(\mathrm{~kW})$ & Total Load $(\mathrm{kW})$ \\
\hline 1 & 166741.39 & - & - & 166741.39 \\
\hline 2 & - & - & - & - \\
\hline 3 & - & - & - & - \\
\hline 4 & - & 1585.748 & - & 1585.748 \\
\hline 5 & - & 442.578 & 867.566 & 1310 \\
\hline 6 & - & - & 9466.9742 & 9466.9742 \\
\hline 7 & - & - & 13507.01646 & 13507.01646 \\
\hline
\end{tabular}


Table 10 TEHL for Cold Streams in Ethylene Plant

\begin{tabular}{|l|c|c|}
\hline Interval & Load of $\mathrm{C}_{1}(\mathrm{~kW})$ & Total Load $(\mathrm{kW})$ \\
\hline 1 & - & - \\
\hline 2 & - & 1483.158 \\
\hline 3 & 1483.158 & 1521.6695 \\
\hline 4 & 1521.6695 & 424.6937 \\
\hline 5 & 424.6937 & 4697.73229 \\
\hline 6 & 4697.73229 & - \\
\hline 7 & - & \\
\hline
\end{tabular}

Load of each stream in Table 9 and 10 is calculated using following equation and stream data given in Table 7 and 8. Next step is cascade diagram as it is shown in Fig. 9. 
As it can be seen from calculation given in Fig. 9 there is no pinch point in the ethylene process.

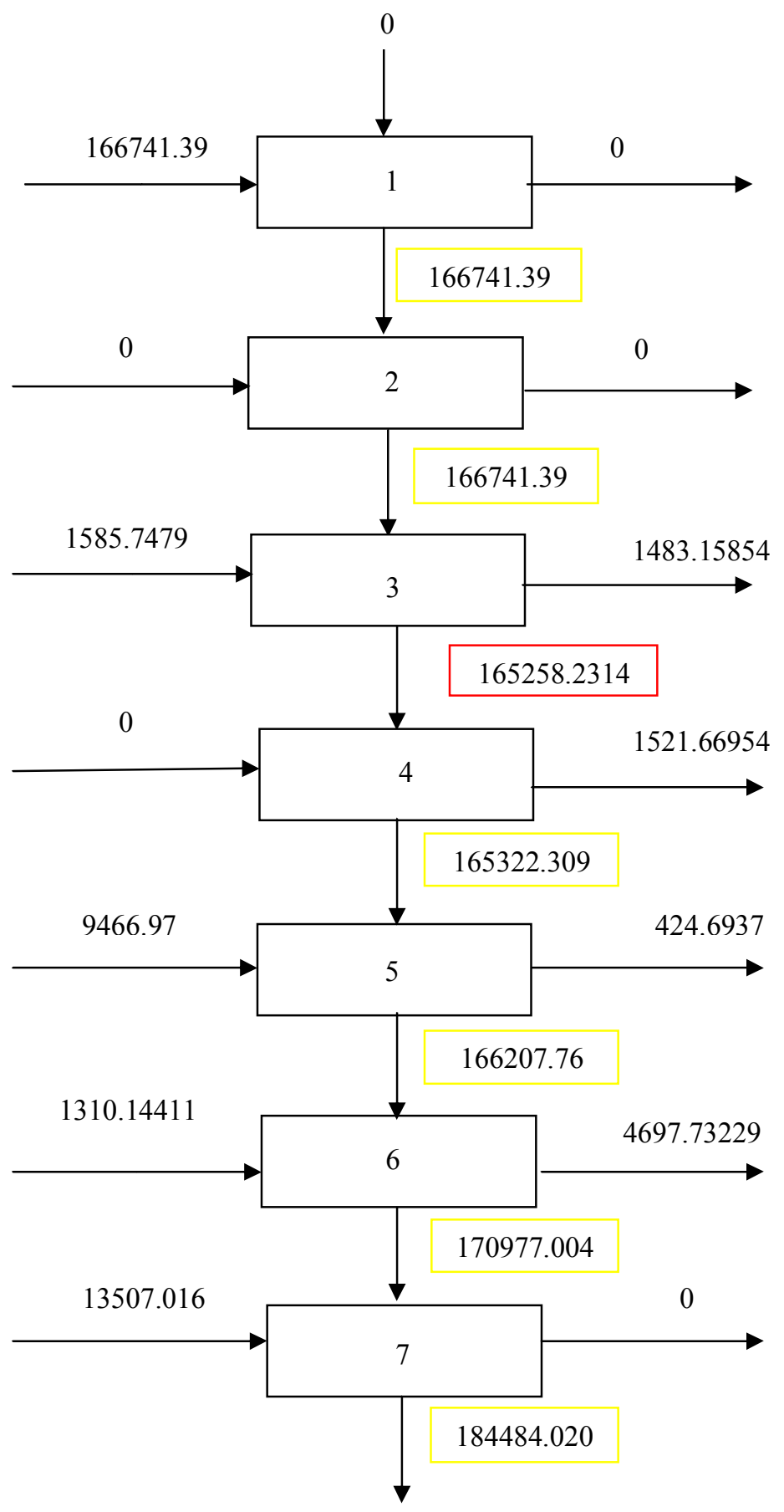

Figure 9 Cascade Diagram for Ethylene Plant 


\title{
CHAPTER IV
}

\section{RESULTS AND ANALYSIS*}

\author{
Steady-State Simulation
}

A static process model is simulated in Aspen plus using the ethylene process base case data which have been scaled up to have 900,000 tons/yr of ethylene as the target product. The model is used to predict the heat of combustion for each flare stream based on components, power and heat requirements. The cracking furnace is modeled based on scaled-up experimental results and the reaction chemistry reported in Table 2. The cracking furnace simulation results are presented in the Table 11 (van Goethem, Barendregt et al. 2013).

Flare stream composition and properties are specified in Tables 11. The composition is estimated from base case material balance, and the energy content for each stream is determined using Aspen simulation software.

Results of Mass balances over carbon, hydrogen, oxygen and sulfur for the entire ethylene process for inlet and outlet stream as shown in Fig. 10 is presented in Table 12. Flare stream energy contents are specified in Table 13 as well.

\footnotetext{
"Part of this chapter is reprinted with permission from "Managing abnormal operation through process integration and cogeneration systems" by Serveh Kamrava, Kerron J. Gabriel, Mahmoud M. ElHalwagi, Fadwa T. Eljack, 2014. Clean Technologies and Environmental Policy, pg. 1-10, Copyright [2014] by Springer Science+ Business Media"
} 
Table 11 Ethylene Process Stream Data

\begin{tabular}{|c|c|c|c|c|c|c|c|c|c|c|c|c|c|c|}
\hline & & 1 & 2 & 3 & 4 & 5 & 6 & 7 & 8 & 9 & 10 & 11 & 12 & 13 \\
\hline \multicolumn{15}{|c|}{ Component mass flow } \\
\hline $\mathrm{H}_{2}$ & \multirow{17}{*}{ Tons/yr } & 0 & 0 & 0 & 0 & 0 & 80859.08 & 80859.08 & 80859.07 & 0.02 & 80859.06 & 0 & 80859.06 & 0 \\
\hline $\mathrm{CH}_{4}$ & & 0 & 0 & 0 & 0 & 3.22 & 137078.8 & 137078.8 & 137078.7 & 0.16 & 137078.6 & 0 & 137078.6 & 0 \\
\hline $\mathrm{C}_{2} \mathrm{H}_{2}$ & & 0 & 0 & 0 & 0 & 0 & 17513.44 & 17513.44 & 17513.27 & 0.29 & 17513.14 & 0 & 17513.14 & 0 \\
\hline $\mathrm{C}_{2} \mathrm{H}_{4}$ & & 0 & 0 & 0 & 0 & 0 & 1068695 & 1068695 & 1068694 & 1.91 & 1068693 & 0 & 1068693 & 0 \\
\hline $\mathrm{C}_{2} \mathrm{H}_{6}$ & & 1389861 & 1389861 & 0 & 0 & 1581464 & 196101.6 & 196101.6 & 196101.4 & 0.25 & 196101.3 & 0 & 196101.3 & 0 \\
\hline $\mathrm{C}_{3} \mathrm{H}_{6}$ & & 0 & 0 & 0 & 0 & 0.02 & 17521.42 & 17521.42 & 17521.31 & 0.19 & 17521.23 & 0 & 17521.23 & 0 \\
\hline $\mathrm{C}_{4} \mathrm{H}_{4}$ & & 0 & 0 & 0 & 0 & 0 & 4777.84 & 4777.84 & 4777.83 & 0.01 & 4777.83 & 0 & 4777.83 & 0 \\
\hline $\mathrm{C}_{4} \mathrm{H}_{6}$ & & 0 & 0 & 0 & 0 & 0 & 23886.9 & 23886.9 & 23886.89 & 0.01 & 23886.89 & 0 & 23886.89 & 0 \\
\hline $\mathrm{C}_{5} \mathrm{H}_{6}$ & & 0 & 0 & 0 & 0 & 0 & 7962.47 & 7962.47 & 7962.39 & 0.13 & 7962.33 & 0 & 7962.33 & 0 \\
\hline $\mathrm{C}_{6} \mathrm{H}_{6}$ & & 0 & 0 & 0 & 0 & 0 & 19105.4 & 19105.4 & 19105.22 & 0.3 & 19105.09 & 0 & 19105.09 & 0 \\
\hline $\mathrm{C}_{8} \mathrm{H}_{8}$ & & 0 & 0 & 0 & 0 & 0 & 3185.88 & 3185.88 & 0 & 3185.88 & 0 & 0 & 0 & 0 \\
\hline $\mathrm{C}_{10} \mathrm{H}_{8}$ & & 0 & 0 & 0 & 0 & 0 & 21) & 3185.61 & 0 & 3185.61 & 0 & 0 & 0 & 0 \\
\hline $\mathrm{C}_{3} \mathrm{H}_{4}$ & & 0 & 0 & 0 & 0 & 0 & 1594.14 & 1594.14 & 1594.14 & 0.01 & 1594.13 & 0 & 1594.13 & 0 \\
\hline $\mathrm{H}_{2} \mathrm{~S}$ & & 488.07 & 0 & 488.07 & 0 & 0 & 0 & 0 & 0 & 0 & 0 & 0 & 0 & 0 \\
\hline $\mathrm{CO}_{2}$ & & 134.27 & 134.27 & 0 & 0 & 134.27 & 134.27 & 134.27 & 134.27 & 0 & 134.27 & 134.27 & 0 & 0 \\
\hline $\mathrm{H}_{2} \mathrm{O}$ & & 2944.16 & 2944.16 & 0 & 524210.5 & 2944.16 & 527154.7 & 527154.7 & 94348.17 & 514578.6 & 12576.03 & 0 & 12576.03 & 12576.03 \\
\hline Total & & 1393428 & 1392939 & 488.07 & 524210.5 & 1584546 & 2108756 & 2108756 & 1669577 & 520953.4 & 1587803 & 134.27 & 1587669 & 12576.03 \\
\hline Temp. & ${ }^{0} \mathrm{~F}$ & 76.91 & 76.91 & 76.91 & 283.19 & 15.7 & 1700.33 & 173.03 & 112.73 & 110.93 & 112.73 & 112.73 & 112.73 & 112.73 \\
\hline Press. & psia & 23 & 23 & 23 & 50 & 23 & 23 & 23 & 23 & 23 & 335 & 335 & 335 & 335 \\
\hline Enthalpy & MMBTU/hr & -384.47 & -384.44 & -0.03 & -679.71 & -446.42 & 8.88 & -560.06 & -8.1 & -795.25 & 89.3 & 89.42 & -0.12 & -25.37 \\
\hline
\end{tabular}


Table 11 Continued

\begin{tabular}{|c|c|c|c|c|c|c|c|c|c|c|c|c|c|}
\hline & & 14 & 15 & $\begin{array}{l}16 \\
\text { (Flare A) }\end{array}$ & 17 & 18 & 19 & $\begin{array}{l}20 \\
\text { (Flare B) }\end{array}$ & 21 & 22 & 23 & $\begin{array}{l}24 \\
\text { (Flare C) }\end{array}$ & 25 \\
\hline \multicolumn{14}{|c|}{ Component mass flow } \\
\hline $\mathrm{H}_{2}$ & \multirow{17}{*}{ Tons/yr } & 80859. & 80859.06 & 80859.06 & 0 & 80859.0 & 80859.0 & 79503.82 & 79503.8 & 79503.82 & 0 & 0 & 0 \\
\hline $\mathrm{CH}_{4}$ & & 13707 & 137078.6 & 137078.6 & 0 & 137078. & 137078. & 137078.6 & 137078. & 137075.4 & 3.22 & 0 & 3.22 \\
\hline $\mathrm{C}_{2} \mathrm{H}_{2}$ & & 17513. & 17513.14 & 17504.81 & 8.34 & 17504.8 & 17504.8 & 0 & 0 & 0 & 0 & 0 & 0 \\
\hline $\mathrm{C}_{2} \mathrm{H}_{4}$ & & 10686 & 1068693 & 1068686 & 6.69 & 1068686 & 1068686 & 1087546 & 1087546 & 187547 & 899999. & 899999.4 & 0 \\
\hline $\mathrm{C}_{2} \mathrm{H}_{6}$ & & 19610 & 196101.3 & 194839 & 1262.27 & 194839 & 194839 & 194839 & 194839 & 3235.97 & 191603. & 0 & 191603 \\
\hline $\mathrm{C}_{3} \mathrm{H}_{6}$ & & 17521. & 17521.23 & 0.02 & 17521.2 & 0.02 & 0.02 & 0.02 & 0.02 & 0 & 0.02 & 0 & 0.02 \\
\hline $\mathrm{C}_{4} \mathrm{H}_{4}$ & & 4777.8 & 4777.83 & 0 & 4777.83 & 0 & 0 & 0 & 0 & 0 & 0 & 0 & 0 \\
\hline $\mathrm{C}_{4} \mathrm{H}_{6}$ & & 23886. & 23886.89 & 0 & 23886.8 & 0 & 0 & 0 & 0 & 0 & 0 & 0 & 0 \\
\hline $\mathrm{C}_{5} \mathrm{H}_{6}$ & & 7962.3 & 7962.33 & 0 & 7962.33 & 0 & 0 & 0 & 0 & 0 & 0 & 0 & 0 \\
\hline $\mathrm{C}_{6} \mathrm{H}_{6}$ & & 19105. & 19105.09 & 0 & 19105.0 & 0 & 0 & 0 & 0 & 0 & 0 & 0 & 0 \\
\hline $\mathrm{C}_{8} \mathrm{H}_{8}$ & & 0 & 0 & 0 & 0 & 0 & 0 & 0 & 0 & 0 & 0 & 0 & 0 \\
\hline $\mathrm{C}_{10} \mathrm{H}_{8}$ & & 0 & 0 & 0 & 0 & 0 & 0 & 0 & 0 & 0 & 0 & 0 & 0 \\
\hline $\mathrm{C}_{3} \mathrm{H}_{4}$ & & 1594.1 & 1594.13 & 0 & 1594.13 & 0 & 0 & 0 & 0 & 0 & 0 & 0 & 0 \\
\hline $\mathrm{H}_{2} \mathrm{~S}$ & & 0 & 0 & 0 & 0 & 0 & 0 & 0 & 0 & 0 & 0 & 0 & 0 \\
\hline $\mathrm{CO}_{2}$ & & 0 & 0 & 0 & 0 & 0 & 0 & 0 & 0 & 0 & 0 & 0 & 0 \\
\hline $\mathrm{H}_{2} \mathrm{O}$ & & 0 & 0 & 0 & 0 & 0 & 0 & 0 & 0 & 0 & 0 & 0 & 0 \\
\hline Total & & $\begin{array}{l}15750 \\
93\end{array}$ & 1575093 & 1498968 & 76124.8 & 1498968 & 1498968 & 1498968 & 1498968 & 407362.2 & 1091606 & 899999.4 & 191606 \\
\hline Temp. & ${ }^{0} \mathrm{~F}$ & 112.73 & 77.99 & -57.01 & 224.69 & -10.57 & 125.33 & 180.59 & -109.93 & -114.43 & 17.87 & -19.39 & -19.39 \\
\hline Press. & psia & 335 & 335 & 334.7 & 336.9 & 464 & 464 & 464 & 464 & 460 & 461.4 & 270 & 270 \\
\hline Enthalpy & MMBTU/hr & 113 & 105.77 & 65.97 & 11.91 & 73.25 & 100.98 & 100.98 & -0.32 & -47.7 & 71.33 & 153.96 & -61.98 \\
\hline
\end{tabular}




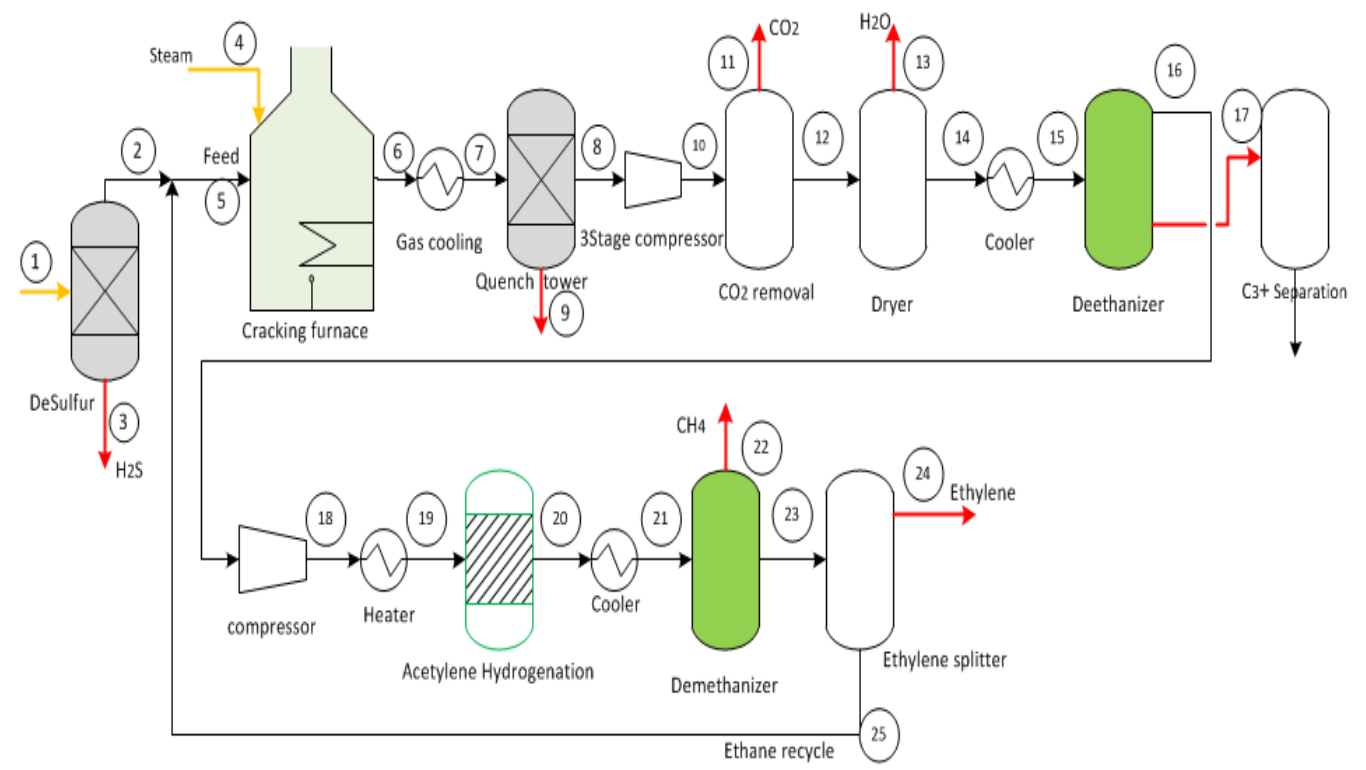

Figure 10 Ethylene Process Inlet and Outlet Streams in Yellow and Red, Respectively

The heat requirement for ethylene, MEA and Claus processes were estimated using process material balance and developed models. For the MEA unit and Claus process, separate Promax models were developed to quantify their energy requirements. The cracking furnace requirements are excluded here. The reason is cracking furnaces operate at very high temperatures $\left(1700.33{ }^{0} \mathrm{~F}\right)$, and the quality of heat required cannot be satisfied with steam coming from cogeneration unit. A summary of the process heating demands are provided in Table 14. 
The ethylene power requirements are estimated to be $32.016 \mathrm{MW}$; this is based on the main 4 compressor units, which are summarized in Table 15. Operating the cogeneration unit with the primary objective to satisfy the heating requirement, resulted in a power production of $0.72 \mathrm{MW}$, see Table 16 .

Table 12 Mass Balance for the Overall Process

\begin{tabular}{|c|c|c|}
\hline components & \multicolumn{2}{|c|}{ Molar flow (lbmole/hr) } \\
\hline & In & Out \\
\hline $\mathrm{H}_{2}$ & 0 & $9.00 \mathrm{E}+03$ \\
\hline $\mathrm{CH}_{4}$ & 0 & $1.95 E+03$ \\
\hline $\mathrm{C}_{2} \mathrm{H}_{2}$ & 0 & $7.56 \mathrm{E}-02$ \\
\hline $\mathrm{C}_{2} \mathrm{H}_{4}$ & 0 & $8.84 E+03$ \\
\hline $\mathrm{C}_{2} \mathrm{H}_{6}$ & 10545.61 & $3.41 \mathrm{E}+01$ \\
\hline $\mathrm{C}_{3} \mathrm{H}_{6}$ & 0 & $9.50 \mathrm{E}+01$ \\
\hline $\mathrm{C}_{4} \mathrm{H}_{4}$ & 0 & $2.09 \mathrm{E}+01$ \\
\hline $\mathrm{C}_{4} \mathrm{H}_{6}$ & 0 & $1.01 \mathrm{E}+02$ \\
\hline $\mathrm{C}_{5} \mathrm{H}_{6}$ & 0 & $2.75 \mathrm{E}+01$ \\
\hline $\mathrm{C}_{6} \mathrm{H}_{6}$ & 0 & $5.58 \mathrm{E}+01$ \\
\hline $\mathrm{C}_{8} \mathrm{H}_{8}$ & 0 & $6.98 \mathrm{E}+00$ \\
\hline $\mathrm{C}_{10} \mathrm{H}_{8}$ & 0 & $5.67 \mathrm{E}+00$ \\
\hline $\mathrm{C}_{3} \mathrm{H}_{4}$ & 0 & $9.08 \mathrm{E}+00$ \\
\hline $\mathrm{H}_{2} \mathrm{~S}$ & 3.267309 & $3.27 \mathrm{E}+00$ \\
\hline $\mathrm{CO}_{2}$ & 0.696097 & $6.96 \mathrm{E}-01$ \\
\hline $\mathrm{H}_{2} \mathrm{O}$ & 6676.141 & $6.68 E+03$ \\
\hline MASS BALA & & \\
\hline $\mathrm{C}$ & 21091.92 & 21091.92 \\
\hline $\mathrm{H}$ & 76625.94 & 76625.94 \\
\hline $\mathrm{O}$ & 6677.533 & 6677.533 \\
\hline $\mathrm{S}$ & 3.267309 & 3.267309 \\
\hline
\end{tabular}


Table 13 Properties of Flare Streams

\begin{tabular}{|l|c|c|c|c|}
\hline Flare stream & $\begin{array}{c}\text { Mass Flow } \\
\text { (tons/yr) }\end{array}$ & $\begin{array}{c}\text { Temperature } \\
\left({ }^{0} \mathrm{~F}\right)\end{array}$ & $\begin{array}{c}\text { Pressure } \\
(\mathrm{psia})\end{array}$ & $\begin{array}{c}\text { Heat of Combustion (Btu/lb) } \\
{\left[14.7 \mathrm{psia}, 77^{\circ} \mathrm{F}\right]}\end{array}$ \\
\hline Flare A & 2248 & -57.01 & 335 & 24090 \\
\hline Flare B & 2248 & 180.59 & 464 & 24056 \\
\hline Flare C & 1350 & -19.39 & 270 & 21648 \\
\hline
\end{tabular}

Table 14 Total Heat Requirement in Ethylene, Sweetening and Claus Process

\begin{tabular}{|l|c|}
\hline Section & Heat (MMBtu/hr) \\
\hline Cracking Furnace & 1065.09 \\
\hline Boiler & 27.73 \\
\hline $\mathrm{H}_{2} \mathrm{~S}$ Removal unit & 30.2 \\
\hline Claus process & -21.12 \\
\hline Net heat Required (excluding furnace) & 36.81 \\
\hline
\end{tabular}

Table 15 Power Requirement in the Ethylene Process

\begin{tabular}{|l|c|}
\hline Section & Power (MW) \\
\hline 3 stage compressors & 29.881 \\
\hline 4th compressor & 2.135 \\
\hline Total & 32.016 \\
\hline
\end{tabular}

Table 16 summarizes the power and heat and steam flow rate that will be generated by cogeneration system. 
Table 16 Output of Cogeneration System

\begin{tabular}{|l|c|}
\hline Targets & Cogeneration system \\
\hline Turbine power output & $0.72 \mathrm{MW}$ \\
\hline Heat generated & $36.81 \mathrm{MMBtu} / \mathrm{hr}$ \\
\hline Steam flow rate & $37602.595 \mathrm{lb} / \mathrm{hr}$ \\
\hline
\end{tabular}

\section{$\mathrm{CO}_{2}$ Emission Calculations}

Three scenarios for comparing $\mathrm{CO}_{2}$ emission are studied here. The bases for comparison for all scenarios are the heating and power demands of $36.81 \mathrm{MMBtu} / \mathrm{hr}$ and $0.72 \mathrm{MW}$, respectively.

- In the first scenario, heat and power are generated separately using fuel gas. The $\mathrm{CO}_{2}$ emissions are estimated for each section separately.

- In the second scenario heat and power are generated using cogeneration unit with fuel gas as feed.

- In the third scenario heat and power are generated using a cogeneration unit, with flare streams as feed. 
Figure 11 and 12 illustrates the three above considered scenarios on qualitative and numerical basis respectively
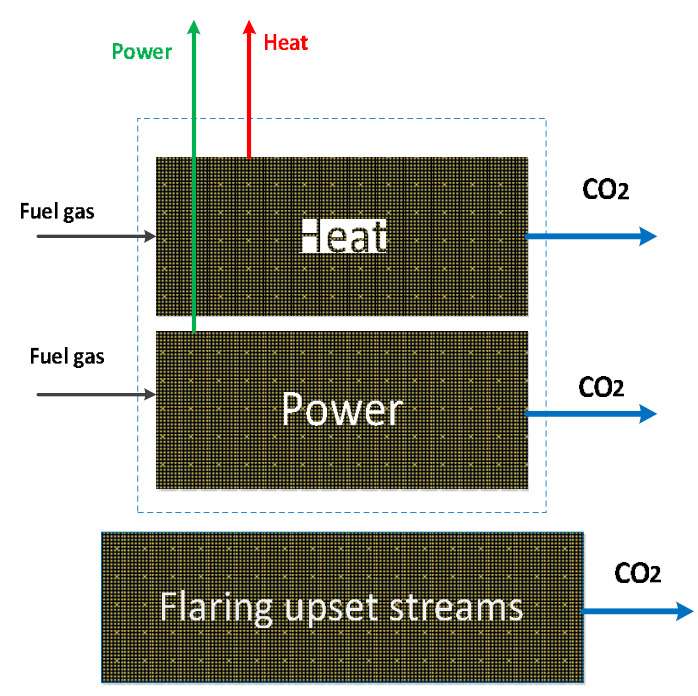

(1)
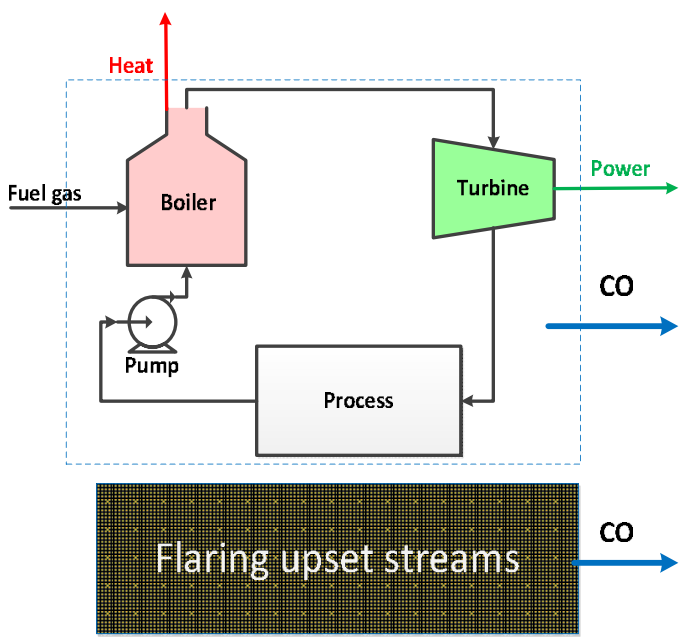

(2)

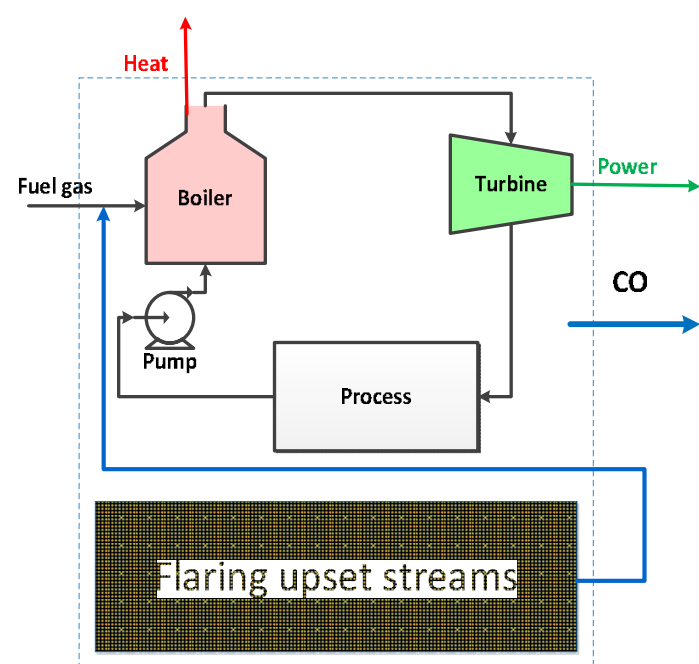

(3)

Figure $11 \mathrm{CO}_{2}$ Emission for Scenario 1, 2 and 3 


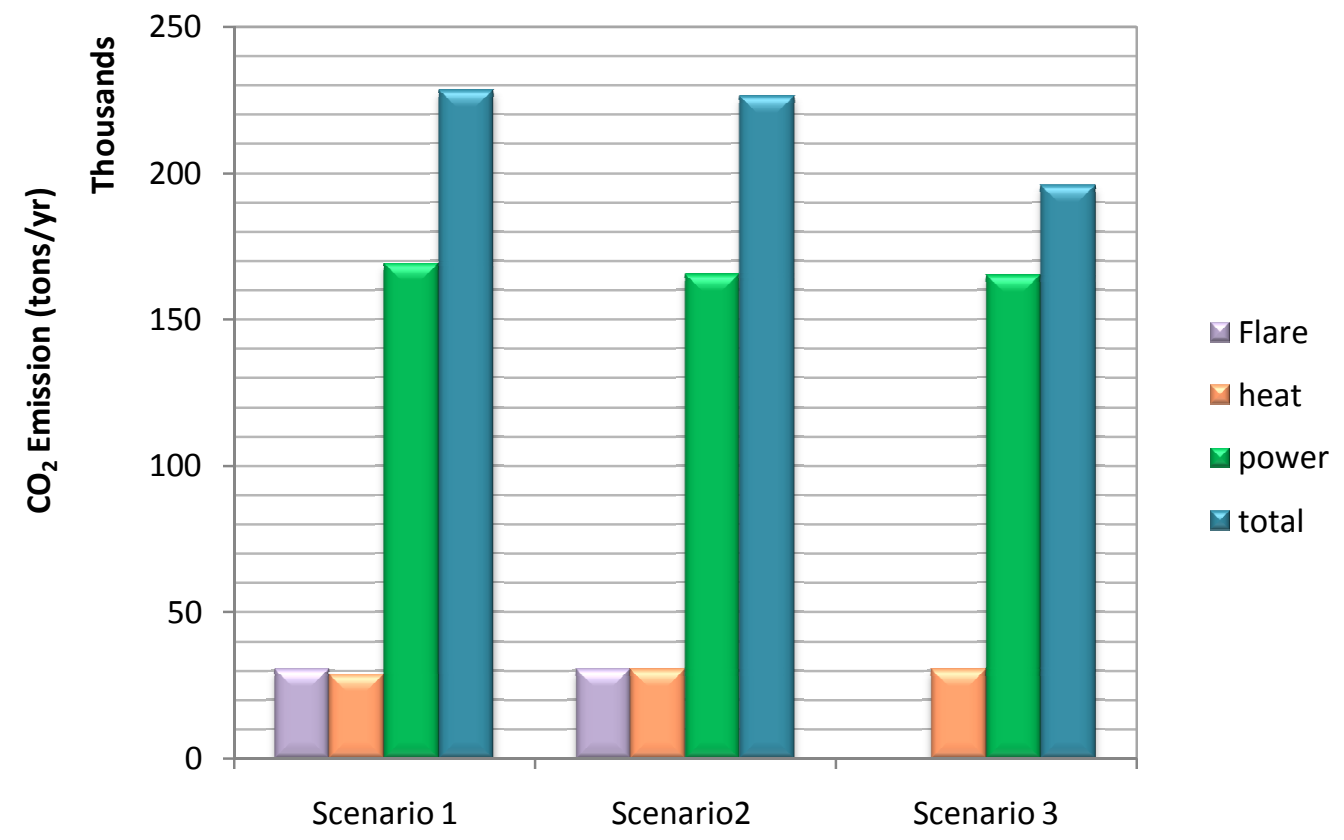

Figure $12 \mathrm{CO}_{2}$ Emission for Scenario 1, 2 and 3 from Different Sources

Figure 12 show the $\mathrm{CO}_{2}$ emissions for all three scenarios. For each scenario, the emission from heat, power and flare are reported. Note that heat and power requirements are the same for all scenarios. The highest emissions are observed in the first scenario where heat and power are generated separately, whereas scenario 2 and 3 use co-gen units. This is mainly due to the amount of fuel gas that was offset by flare streams as feed. Detailed calculations in Cogeneration unit are as described furthermore. 


\section{Scenario 1:}

$\mathrm{CO}_{2}$ from power: $\quad 32.016 \mathrm{MW} \times 1000 \frac{\mathrm{kW}}{\mathrm{MW}} \times 0.599 \frac{\mathrm{kg} \mathrm{CO}}{\mathrm{kW} \cdot \mathrm{h}} \times 8000 \frac{\mathrm{h}}{\mathrm{yr}} \times 0.0011 \frac{\text { tons }}{\mathrm{kg}}=$ $169117 \frac{\text { tons }}{y r}$

$\mathrm{CO}_{2}$ from heat: $\frac{\boldsymbol{Q}_{\text {process }}}{\eta_{\text {process }}} \times \frac{\$}{M M B t u}=\frac{36.81 \frac{M M B t u}{h}}{0.8} \times 70.5 \frac{\mathrm{kgCO}}{M M B t u} \times 8000 \frac{\mathrm{h}}{\mathrm{yr}} \times 0.0011 \frac{\text { tons }}{\mathrm{kg}}=$ $28606 \frac{\text { tons }}{y r}$

$\mathrm{CO}_{2}$ from Flare $=30513 \frac{\text { tons }}{y r}$

Total $=\mathrm{CO}_{2}$ from power $+\mathrm{CO}_{2}$ from heat $+\mathrm{CO}_{2}$ from flare $=228236$ tons $/ \mathrm{yr}$

Scenario 2:

$\mathrm{CO}_{2}$ from power: $(32.016-0.72) \mathrm{MW} \times 1000 \frac{\mathrm{kW}}{\mathrm{MW}} \times 0.599 \frac{\mathrm{kgCO}}{\mathrm{kW} \cdot \mathrm{h}} \times 8000 \frac{\mathrm{h}}{\mathrm{yr}} \times 0.0011 \frac{\mathrm{tons}}{\mathrm{kg}}=$ $165314 \frac{\text { tons }}{y r}$

$\mathrm{CO}_{2}$ from heat: $\frac{Q_{\text {process }}}{\eta_{\text {process }}} \times \frac{\$}{M M B t u}=\frac{36.81 \frac{M M B t u}{\mathrm{~h}}}{0.75} \times 70.5 \frac{\mathrm{kgCO}}{M M B t u} \times 8000 \frac{\mathrm{h}}{\mathrm{yr}} \times 0.0011 \frac{\text { tons }}{\mathrm{kg}}=$ $30513 \frac{\text { tons }}{y r}$

CO2 from Flare: $30513 \frac{\text { tons }}{y r}$

Total $=\mathrm{CO}_{2}$ from power $+\mathrm{CO}_{2}$ from heat $+\mathrm{CO}_{2}$ from flare $=226340$ tons $/ \mathrm{yr}$

Scenario 3:

$\mathrm{CO}_{2}$ from power: $(32.016-0.72) \mathrm{MW} \times 1000 \frac{\mathrm{kW}}{\mathrm{MW}} \times 0.599 \frac{\mathrm{kgCO}}{\mathrm{kW} \cdot \mathrm{h}} \times 8000 \frac{\mathrm{h}}{\mathrm{yr}} \times 0.0011 \frac{\mathrm{tons}}{\mathrm{kg}}=$ $165314 \frac{\text { tons }}{y r}$ 
$\mathrm{CO}_{2}$ from heat: $\frac{Q_{\text {process }}}{\eta_{\text {process }}} \times \frac{\$}{M M B t u}=\frac{36.81 \frac{M M B t u}{\mathrm{~h}}}{0.75} \times 70.5 \frac{\mathrm{kgCO} \mathrm{O}_{2}}{M M B t u} \times 8000 \frac{\mathrm{h}}{\mathrm{yr}} \times 0.0011 \frac{\mathrm{tons}}{\mathrm{kg}}=$ $30513 \frac{\text { tons }}{y r}$

Total $=\mathrm{CO}_{2}$ from power $+\mathrm{CO}_{2}$ from heat $=195827$ tons $/ \mathrm{yr}$

Reduction (scenario 1 -scenario3) $=32409$ tons $/ \mathrm{yr}$

\section{Cost Evaluation}

The cost benefit for utilizing a cogeneration scheme and flare gases as a fuel source is compared with the design choice of heating being supplied by a separate natural gas fired boiler and power being supplied by the grid. The cogeneration model is used to quantify the economic implications using cost exponents and other estimates from literature (Peters, Timmerhaus et al. 2002). The operating cost savings is based on a heating and power cost of $4 \$ \mathrm{MMBtu}$ and $0.08 \$ / \mathrm{kWh}$, respectively. For this study we also assume a plant on-stream factor of ninety percent (90\%) which results in an attractive simple payback period of 0.25 year. Some of detailed calculations in Cogeneration unit are as described furthermore.

\section{Heat production (no cogeneration):}

Electricity cost: $32.016 M w \times 0.08 \frac{\$}{k w . h} 24 \frac{h}{d a y} \times 1000 \frac{k w}{M w}=\$ 61470.72 /$ day

Fuel cost: $\frac{Q_{\text {process }}}{\eta_{\text {process }}} \times \frac{\$}{M M B t u}=36.81 \frac{M M B t u}{h} \times \frac{1}{0.75} \times 4 \frac{\$}{M M B t u} \times 24 \frac{h}{\text { day }}=\$ 4711.68 /$ day

Total cost: $\$ 66182 /$ day 


\section{Cogeneration:}

Electricity cost: $\quad(32.016-0.72) M w \times 0.08 \frac{\$}{k w \cdot h} 24 \frac{h}{d a y} \times 1000 \frac{k w}{M w}=\$ 60088.32 /$ day

Savings analysis:

Cost savings $=$ Power savings + Heating savings

$$
\begin{aligned}
& \left.=\left[\frac{(\$ 61470.72-\$ 60088.32)}{\text { day }}+\frac{\$ 4711.68}{\text { day }}\right]\left(\frac{\text { savings }}{\text { day }}\right) \times \frac{365 \text { day }}{\text { year }} \times 0.9 \text { (onstream factor }\right) \\
& =\$ 2001905.2 / \text { year }
\end{aligned}
$$

As shown in Table 17, the cogeneration scheme has an increased total capital investment of $\$ 1.947$ million but decreased operating cost by $\$ 60,000$ per day. Additional results are also summarized in Table 18.

Table 17 Cost Evaluation

\begin{tabular}{|l|c|c|}
\hline Capital investment & Heat production System & Cogeneration system \\
\hline Boiler cost & $1,425 \times 10^{3} \$$ & $1,515 \times 10^{3} \$$ \\
\hline Turbine cost & $0 \$$ & $431 \times 10^{3} \$$ \\
\hline Total investment & $1,425 \times 10^{3} \$$ & $1,947 \times 10^{3} \$$ \\
\hline Operating cost & & \\
\hline Fuel cost & $4.8 \times 10^{3} \$ /$ day & - \\
\hline Electricity cost & $61 \times 10^{3} \$ /$ day & $60 \times 10^{3} \$ /$ day \\
\hline Total operating cost & $66 \times 10^{3} \$ /$ day & $60 \times 10^{3} \$ /$ day \\
\hline
\end{tabular}


Table 18 Evaluation

\begin{tabular}{|c|c|}
\hline \multicolumn{2}{|c|}{ Evaluation } \\
\hline Additional investment & $522 \times 10^{3} \$$ \\
\hline Operating cost saving & $2.07 \times 10^{6} \$ / \mathrm{yr}$ \\
\hline Payback period & 0.253 year \\
\hline $\mathrm{CO}_{2}$ emission reduction & $3.24 \times 10^{4}$ tons $/ \mathrm{yr}$ \\
\hline
\end{tabular}




\section{CHAPTER V}

\section{SAFETY}

All equipment are designed to operate in a certain range of properties of a fuel. It is important to have a proper fuel for boiler and turbine to maintain a long life time along with safe operation. There are properties that should be specified in order to determine if a fuel is qualified to be sent to a cogeneration unit. Some of the most important properties that indicate fuel qualities are wobbe index (WI), lower and upper flammability limits (LFL, UFL), lower heating value (LHV), specific gravity (SG), Flammability Ratio (FR), etc. (Hasan, Karimi et al. 2011).

\section{Wobbe Index}

Since flare streams are not continuous and usually feed to the cogeneration unit is natural gas, WI is used as a safety metric for the new fuel to the boiler to meet the requirements. As mentioned in chapter 2 natural gas has a wobbe number between 1310 and 1390. In Table 13 different properties for estimating the WI is listed. WI is estimated from equation (8).

Lower heating value indicates direct energy content of a fuel stream and it depends on fuel stream composition. Energy requirement of various units are usually specified in term of LHV (Hasan, Karimi et al. 2011). Because of the impact of fuel temperature on the actual volumetric fuel flow rate, a temperature correction factor is used for WI. In the following equation $T_{R}$ is the reference temperature which is $288{ }^{\circ} \mathrm{K}$ and $T_{g}$ is the Fuel 
temperature (Elliott, Kurz et al. 2004, Hasan, Karimi et al. 2011). LHV depends on gas composition and we assumed that it does not change with temperature.

$\mathrm{WI}=\left(\frac{\text { Lower heating value }}{\sqrt{\text { specific gravity }}}\right) \times \sqrt{\frac{T_{R}}{T_{g}}}$

Table 19 Flare Streams Properties

\begin{tabular}{|c|c|c|c|c|c|c|c|}
\hline & & \multicolumn{6}{|c|}{ Flare Streams } \\
\hline & & $\mathrm{A}$ & $\mathrm{B}$ & $\mathrm{C}$ & $\mathrm{A}+\mathrm{B}$ & $\mathrm{A}+\mathrm{C}$ & $\mathrm{B}+\mathrm{C}$ \\
\hline \multirow{3}{*}{ Properties } & $\mathrm{T}\left({ }^{\circ} \mathrm{F}\right)$ & -57.01 & 180.59 & -19.39 & 62.06 & 0.356 & 115.376 \\
\hline & $\mathrm{P}$ (psia) & 334.696 & 464 & 270 & 334.696 & 279 & 270 \\
\hline & Flowrate (lbmole/hr) & 21424.1 & 21270.7 & 7319.49 & 42694.78 & 28743.59 & 28590.2 \\
\hline \multirow{3}{*}{$\begin{array}{l}\text { ASPEN } \\
\text { Results }\end{array}$} & LHV (Btu/scf) & 929.76 & 935.033 & 1499.05 & 932.388 & 1074.73 & 1079.43 \\
\hline & S.G (1atm, $\left.288^{0} \mathrm{~K}\right)$ & 0.348 & 0.347 & 0.356 & 0.347 & 0.351 & 0.350 \\
\hline & WI (Btu/cuft) & 1367.3 & 1370.3 & 1634.1 & 1368.79 & 1437.66 & 1440.2 \\
\hline \multicolumn{2}{|c|}{$\mathrm{WI}=\left(\frac{\text { Lower heating value }}{\sqrt{\text { specific gravity }}}\right) \times \sqrt{\frac{T_{R}}{T_{g}}}$} & 1788.3 & 1428.2 & 2726.2 & 1577.76 & 1925.69 & 1732.3 \\
\hline \multicolumn{2}{|c|}{$\mathrm{WI}=\left(\frac{\text { Lower heating value }}{\sqrt{\text { specific gravity }}}\right)$} & 1576 & 1587.3 & 2512.4 & 1582.82 & 1814.03 & 1824.5 \\
\hline
\end{tabular}

WI for flare streams is calculated from three different methods including: ASPEN software (method 1$)$, calculation from equation $8(\operatorname{method} 2)$ and finally calculation from WI equation without considering temperature correction factor (method 3). From Table 20 it is seen that based on three different method, three different result is achieved 
shown in Fig. 13. Since boilers are usually deigned based on properties of natural gas therefore WI of different fuels should be compared to WI of natural gas.

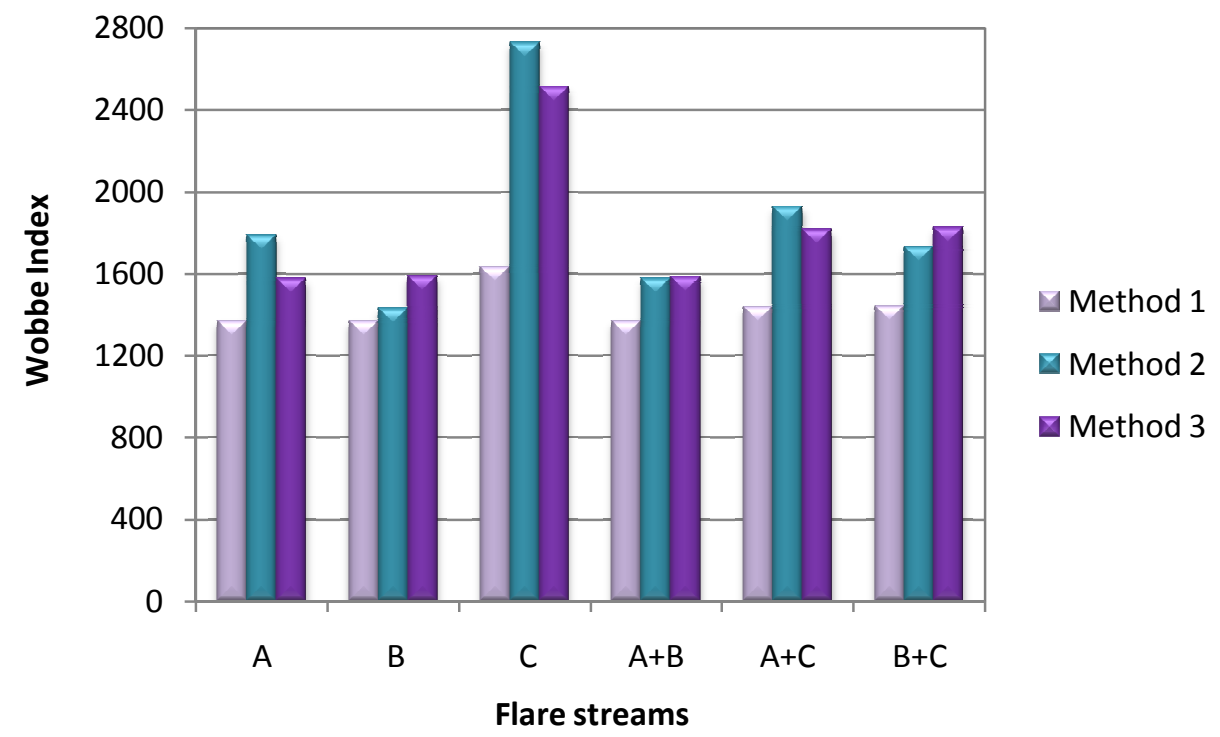

Figure 13 Comparison of Three Different Methods for WI of Different Flare Streams

All flare streams in method 2 and 3 and also flare streams $\mathrm{C}, \mathrm{A}+\mathrm{C}$ and $\mathrm{B}+\mathrm{C}$ in method 1 ; have WI higher than maximum WI of natural gas which is 1390 . Therefore these streams should be mixed with natural gas (Fig. 14) to have the proper WI for the designed boiler. 


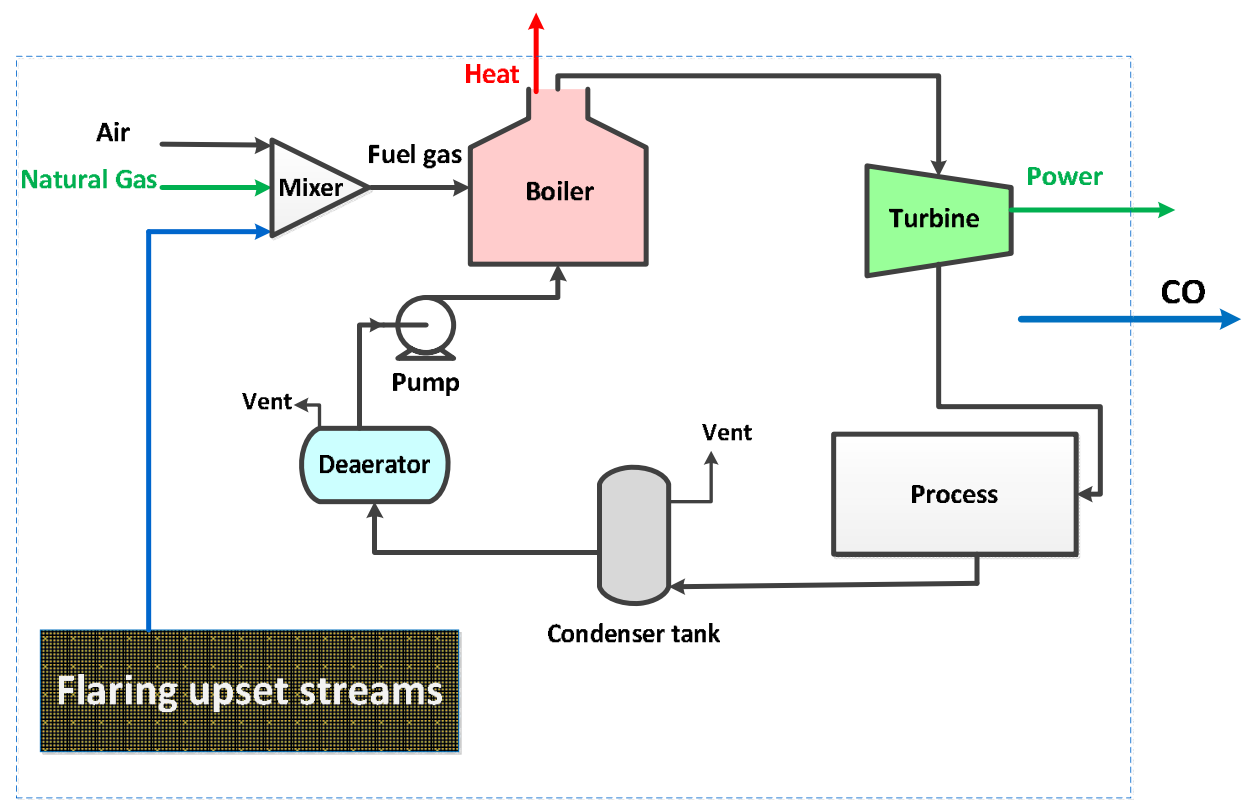

Figure 14 Cogeneration System Utilizing Mixed Fuels

\section{Flammability Limits}

Mixture of fuel and air only burn in a specific range. Flammability limits for different vapor fuel compositions are estimated experimentally. The test is based on igniting different concentration of vapor-air mixture to determine the range of flammability of a specific gas. This means that lower or higher than a specific concentration the fuel would be too lean and too rich, respectively to be burned. Flammability characteristics of different flare stream composition that are supposed to be burned in boiler are presented in Table 21. The equations for calculating flammability limits for a mixture are shown in equations (9) and (10) (Daniel A. Crowl 2011). 
$\mathrm{LFL}_{\text {mix }}=\frac{1}{\sum \frac{y_{i}}{L F L_{i}}}$

$\mathrm{UFL}_{\text {mix }}=\frac{1}{\sum \frac{y_{i}}{U F L_{i}}}$

Where LFL and UFL are the lower and upper flammable limit for component $\mathrm{i}$ (in volume $\%$ ) of component $\mathrm{i}$ in fuel and air, $\mathrm{y}_{\mathrm{i}}$ is the mole fraction of component $\mathrm{I}$ on a combustible basis and $\mathrm{n}$ is the number of combustible species (Daniel A. Crowl 2011). For natural gas flammability limit is between 4.5- 15 (EPA 2008).

Another measure of fuel quality is flammability ratio (FR). FR is defined as the ratio of upper flammability limit to lower flammability limit of a fuel gas to that of natural gas. FR for different fuel streams are shown in Table 21. When a fuel gas contain high content of hydrogen and/or Carbon monoxide then FR will be higher than 1 and when it contains high content of nitrogen and/or carbon dioxide then FR will be lower than 1 . High FR may cause problems such as: damage in combustion system or explosion due to auto ignition of the fuel at turbine exhaust. To avoid these problems streams should be mixed with inert components. The FR requirement for different systems might vary between 1-10 (Hasan, Karimi et al. 2011). 
Table 20 Mole Fraction and Flammability Limit vol. \% Fuel in air of Flare Streams

\begin{tabular}{|c|c|c|c|c|c|c|}
\hline & \multicolumn{4}{|c|}{$\mathrm{Y}(\%)$} & \multicolumn{2}{|c|}{ Vol. (\%) [7] } \\
\hline & Flare A & Flare B & Flare C & Flare $\mathrm{A}+\mathrm{B}$ & LFL & UFL \\
\hline $\mathrm{H}_{2}$ & 0.4271598 & 0.4230290 & 0 & 0.4251018 & 4 & 75 \\
\hline $\mathrm{CH}_{4}$ & 0.0909949 & 0.0916510 & 0 & 0.0913218 & 5 & 15 \\
\hline $\mathrm{C}_{2} \mathrm{H}_{2}$ & 7.15942E-3 & 0 & 0 & 0.00359258 & 2.5 & 80 \\
\hline $\mathrm{C}_{2} \mathrm{H}_{4}$ & 0.4056819 & 0.4158183 & 0 & 0.4107319 & 2.7 & 36 \\
\hline $\mathrm{C}_{2} \mathrm{H}_{6}$ & 0.0690039 & 0.0695015 & 1 & 0.0692518 & 3 & 12.5 \\
\hline $\mathrm{C}_{3} \mathrm{H}_{6}$ & 4.09272E-9 & 4.12223E-9 & 0 & $4.15155 \mathrm{E}-09$ & 2 & 11.1 \\
\hline $\mathrm{C}_{4} \mathrm{H}_{4}$ & $8.4029 \mathrm{E}-14$ & $8.4635 \mathrm{E}-14$ & 0 & $8.5236 \mathrm{E}-14$ & 2.22 & 54.93 \\
\hline $\mathrm{C}_{4} \mathrm{H}_{6}$ & $9.0080 \mathrm{E}-13$ & $9.0729 \mathrm{E}-13$ & 0 & $9.1377 \mathrm{E}-13$ & 2 & 12 \\
\hline $\mathrm{C}_{5} \mathrm{H}_{6}$ & $3.4278 \mathrm{E}-18$ & 0 & 0 & $1.7384 \mathrm{E}-18$ & 1.71 & 14.61 \\
\hline $\mathrm{C}_{6} \mathrm{H}_{6}$ & $6.9588 \mathrm{E}-21$ & 0 & 0 & $3.5285 \mathrm{E}-21$ & 1.4 & 7.1 \\
\hline $\mathrm{C}_{3} \mathrm{H}_{4}$ & $6.2076 \mathrm{E}-10$ & $6.2524 \mathrm{E}-10$ & 0 & $6.2969 \mathrm{E}-10$ & 2 & 12.5 \\
\hline
\end{tabular}

The result of LFL mix and UFL mix for three flare streams of $\mathrm{A}, \mathrm{B}$ and $\mathrm{C}$ and mixture stream of $\mathrm{A}+\mathrm{B}$ are as described in Table 22. 
Table 21 LFL and UFL, FR and Heat of Combustion for Flare Streams

\begin{tabular}{|l|c|c|c|c|}
\hline Flare Stream & LFL & UFL & FR & $\Delta \mathrm{H}_{\mathrm{C}}(\mathrm{Kcal} / \mathrm{mole})$ \\
\hline A & 3.321 & 34.9373 & 3.5 & 213.64456 \\
\hline B & 3.319 & 34.6487 & 3.47 & 214.88255 \\
\hline A+B & 3.320 & 34.782 & 3.49 & 214.265 \\
\hline C & 3 & 12.5 & 1.38 & 201.10326 \\
\hline
\end{tabular}

Since WI for stream $\mathrm{C}$ does not meet the range for boiler designed for natural gas, mixture estimate of LFL and UFL are only presented for stream A and B. The LFL and UFL for all streams have wider range than natural gas which is an advantage, because they could be burn in a wider range of mixture with air.

Flammability Limit Dependence on Temperature

The flammability limit range increases with temperature as shown in equation (11) and (12) (Daniel A. Crowl 2011).

$\mathrm{LFL}_{\mathrm{T}}=\mathrm{LFL}_{25}-\frac{0.75}{\Delta H_{C}}(\mathrm{~T}-25)$

$\mathrm{UFL}_{\mathrm{T}}=\mathrm{UFL}_{25}+\frac{0.75}{\Delta H_{C}}(\mathrm{~T}-25)$

Where, $\Delta \mathrm{H}_{\mathrm{C}}$ is the net heat of combustion ( $\left.\mathrm{kcal} / \mathrm{mole}\right)$ and $\mathrm{T}$ is the temperature $\left({ }^{0} \mathrm{C}\right)$. These equations are very approximate and work for a very limited number of hydrocarbons for a special range of temperature (Daniel A. Crowl 2011).

Based on the above equation flammability ranges are estimated for flare streams of $\mathrm{A}, \mathrm{B}$ and $\mathrm{A}+\mathrm{B}$ for different temperatures. 

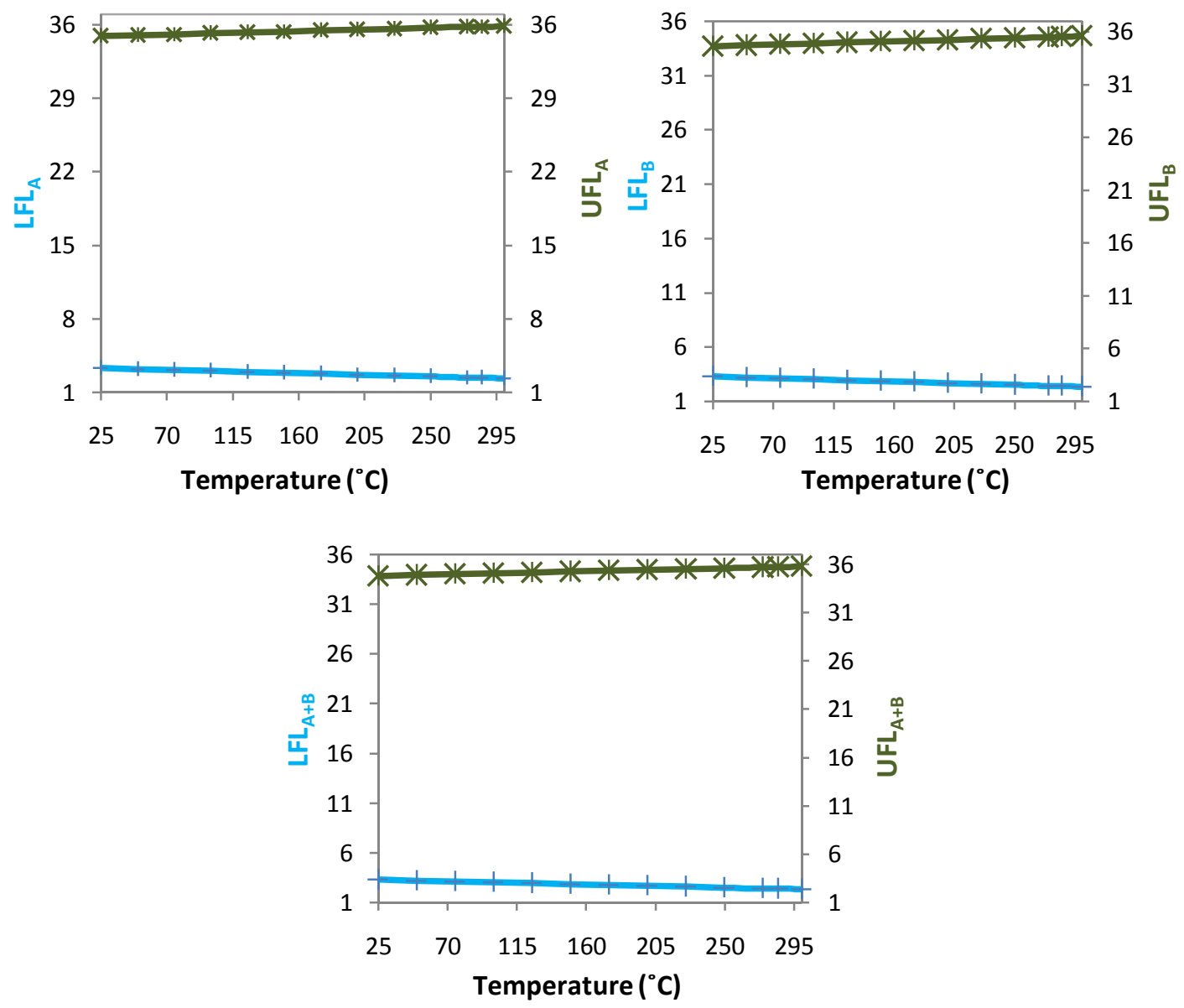

Figure 15 Dependency of LFL and UFL of Stream A, B and A+B versus Temperature

Dependency of flammability and temperature are shown in Fig. 15. As it can be seen in the Fig. 15 as the temperature increase the LFL and UFL will have a wider range between them. This means that the fuel can be ignited easier with temperature rise.

Flammability Limit Dependence on Pressure

Pressure has little effect on LFL but UFL increase dramatically with pressure increase as shown in equation (13) (Daniel A. Crowl 2011). 
$\mathrm{UFL}_{\mathrm{P}}=\mathrm{UFL}+20.6(\log \mathrm{P}+1)$

Where $\mathrm{P}$ is the pressure (mega pascals absolute) and UFL is the upper flammable limit (volume $\%$ of fuel plus air at $1 \mathrm{~atm}$ ).

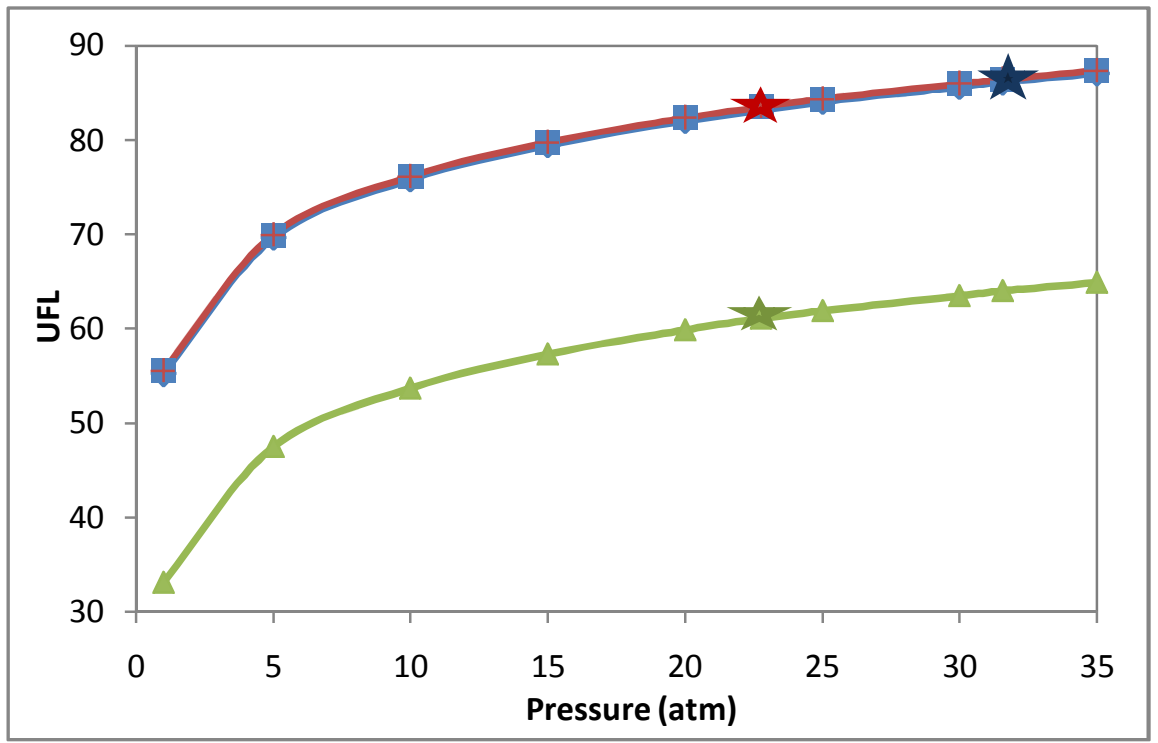

Figure 16 UFL of Stream A (--), B (--) and C (--) versus Pressure (atm)

From Fig. 16 it is obvious that all UFL of streams increase with increase in pressure which means that fuel will be ignited even in richer composition in higher pressures.

\section{Limiting Oxygen Concentration and Inerting}

For preventing an explosion besides controlling concentration and composition of the fuel, controlling the concentration of oxygen is extremely an important factor. Reducing concentration of oxygen inhibit any explosion therefore a minimum oxygen 
concentration (MOC) which below this concentration reaction will not happen is calculated. MOC is also called limiting oxygen concentration (LOC) equation (14) or maximum safe oxygen concentration (MSOC) (Daniel A. Crowl 2011).

$\mathrm{LOC}=\left(\frac{L F L-C_{L O C} U F L}{1-C_{L O C}}\right)\left(\frac{U F L_{O}}{U F L}\right)$

$\mathrm{UFL}_{O}$ is the oxygen concentration at the upper flammable limit (vol. \% oxygen in air) which can be calculated as shown in equation (15).

$\mathrm{UFL}_{\mathrm{O}}=(0.21)(100-\mathrm{UFL})$

$\mathrm{C}_{\mathrm{LOC}}$ is a fitting constant equal to -1.11 which is a good fit for many hydrocarbons.

$\mathrm{UFL}_{\mathrm{O}}=(0.21)(100-34.782)=13.695$

$\mathrm{LOC}_{\mathrm{A}+\mathrm{B}}=\left(\frac{3.320+1.11 \times 34.782}{1+1.11}\right)\left(\frac{13.695}{34.782}\right)=7.824$ vol. $\% \mathrm{O}_{2}$

\section{Hazards Analysis}

Risk assessment is one of the key tools for providing safety to industries. In process industries many techniques have been applied for risk assessment such as; What-if Analysis, Safety Review, Relative Ranking, Checklist Analysis, Preliminary Hazard Analysis, Hazard and Operability Study (HAZOP), Failure Modes and Effects Analysis (FMEA), Fault Tree Analysis (FTA), Event Tree Analysis (ETA), Human Reliability Analysis (HRA). Hazard and operability study is a way to identify and document hazards and operability problems (Labovský, Švandová et al. 2007, Daniel A. Crowl 
2011, Marhavilas, Koulouriotis et al. 2011). Hazards occur in a plant due to deviation from normal operation. This systematic examination of equipment was developed in 70 'sby ICI to determine any failure. HAZOP analysis aim is (Marhavilas, Koulouriotis et al. 2011):

- Identify possible deviations (abnormal operation) and then causes of the deviation (examples: high temperature, high pressure, change in composition, etc.)

- evaluating probability of the cause

- Consequences of the deviation and severity level ( with and without safe guard)

- Evaluating effectiveness of existing measures

- Studying appropriate tools to prevent or mitigate any following accident.

A schematic of $\mathrm{H}$ flowchart is shown in Fig. 17 which will more explain the steps mentioned above (Khan and Abbasi 1997, Marhavilas, Koulouriotis et al. 2011): 


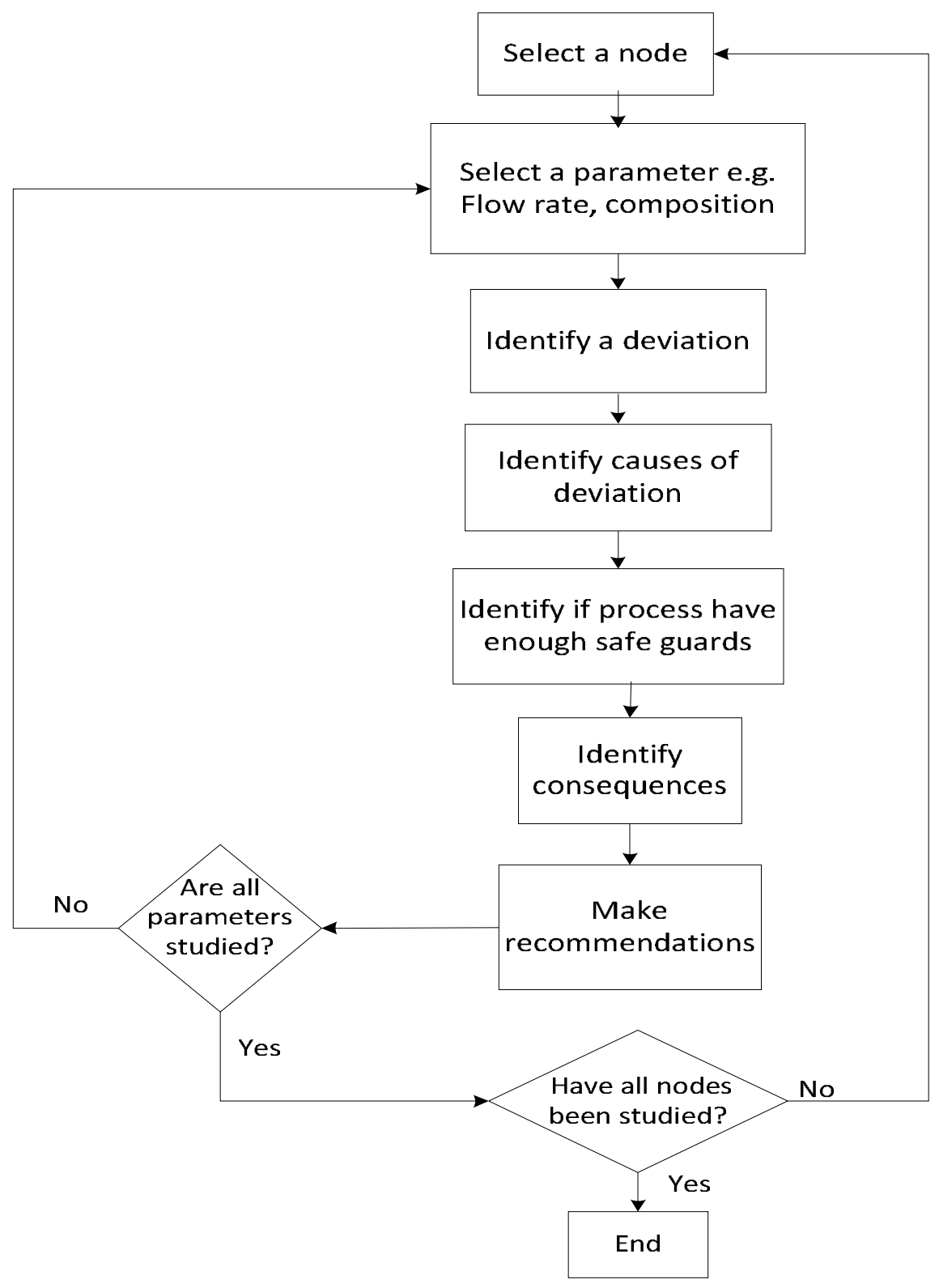

Figure 17 Hazards Flowchart

A HAZOP study has following steps (Rossing, Lind et al. 2010):

- Pre-meeting: purpose and objective of study is defined. Then all required information is collected. 
- Meeting: the technique is reviewed, specific objectives are determined.

- Post-meeting: results of studies by each group member are reported.

However HAZOP study requires a considerable amount of time and also piping and instrument diagram (P\&ID) and finally expert people to identify all possible causes to have proper recommendations (Rossing, Lind et al. 2010, Marhavilas, Koulouriotis et al. 2011).

Disturbances while operation such as failure in meeting the fuel requirement for the boiler in cogeneration can lead to a deviation from normal operation.

Boiler can receive gas that has an off-spec composition which may cause a reduction or increase in tube temperature tubes in the boiler can fail if exposed to a high temp for long. Because flare gases are going to the boiler the spec may be high in hydrogen which is explosive and may be catastrophic.

In 1996, an incident occurred due to low water level in a high temperature boiler in a process plant. Failure of the low level interlock and also failure to apply proper procedure and Low water level were the reasons to this incident. As a result, the boiler dry fired and serious internal damage happened to the boiler and steam drum. This case was a near miss (Mahnken 2001).

Hazards analysis summary is presented in Table 23 for different parameters and deviations with recommendations (Musyafa and Adyagsa 2012). The most important 
parameters in a pipe line going to a boiler is the composition, temperature, flow rate and pressure which has been studied here. 
Table 22 Hazards Analysis

\begin{tabular}{|c|c|c|c|c|c|}
\hline Parameter & Deviation & Causes & Consequences & Safe guards & recommendations \\
\hline Composition & As well as & $\begin{array}{l}\text { High hydrogen content, } \\
\text { high WI, too lean } \\
\text { mixture of fuel }\end{array}$ & $\begin{array}{c}\text { Failing in start-up, Flash back, } \\
\text { pulsation, Flame out }\end{array}$ & Sensors and alarms & $\begin{array}{l}\text { Threshold should be defined to } \\
\text { detect deviation, online } \\
\text { concentration measurement, flow } \\
\text { alarm }\end{array}$ \\
\hline \multirow{3}{*}{ Flow } & No & $\begin{array}{l}\text { Pipeline rupture, no feed } \\
\text { inlet, blockage, failure of } \\
\text { control valve }\end{array}$ & $\begin{array}{l}\text { Interruption to process operation } \\
\text { due to deviation of feed flow }\end{array}$ & $\begin{array}{l}\text { Low flow sensors, } \\
\text { regular pipe inspection }\end{array}$ & Regular pipe inspection, \\
\hline & More & $\begin{array}{l}\text { Greater fluid density, } \\
\text { increased pumping } \\
\text { capacity, Malfunction of } \\
\text { control valve }\end{array}$ & $\begin{array}{l}\text { Failure, leak and release of fuel } \\
\text { and if ignition then possibility of } \\
\text { fire, Potential variable flow in the } \\
\text { system, potential overloading, }\end{array}$ & $\begin{array}{l}\text { Manual control valve, } \\
\text { high flow alarm }\end{array}$ & $\begin{array}{c}\text { Regular valve and pipe } \\
\text { inspection, install a control valve }\end{array}$ \\
\hline & Less & $\begin{array}{c}\text { Line restriction, } \\
\text { defective pumps, fouling } \\
\text { of valves }\end{array}$ & $\begin{array}{c}\text { disturbance in process operation } \\
\text { due to deviation of feed flow, } \\
\text { Impact on quality }\end{array}$ & $\begin{array}{l}\text { Point gas detector, low } \\
\text { flow signal }\end{array}$ & $\begin{array}{c}\text { Installing a control valve, Valve } \\
\text { inspection }\end{array}$ \\
\hline \multirow[t]{2}{*}{ Pressure } & High & $\begin{array}{c}\text { Failure of pressure relief } \\
\text { valves, pressure } \\
\text { indicator and level } \\
\text { control valve } \\
\end{array}$ & $\begin{array}{l}\text { Overfilling of tank, Pipeline } \\
\text { rupture, failure to mitigate } \\
\text { consequences }\end{array}$ & $\begin{array}{l}\text { Pressure indicators, } \\
\text { pressure relief valves, } \\
\text { equipment inspection }\end{array}$ & $\begin{array}{l}\text { Regular maintenance and repair, } \\
\text { regular maintenance of PI }\end{array}$ \\
\hline & Low & $\begin{array}{c}\text { Leakage of the pipeline, } \\
\text { technical problem }\end{array}$ & $\begin{array}{l}\text { Failure to monitor pressure, } \\
\text { failure to mitigate consequences }\end{array}$ & Pressure indicator & PI installation, regular examine \\
\hline Temperature & high & $\begin{array}{l}\text { Indicator not working, } \\
\text { environmental effect }\end{array}$ & $\begin{array}{l}\text { Overpressure, Pipeline or tank } \\
\text { rupture, failure to mitigate } \\
\text { consequences }\end{array}$ & Temperature indicator & $\begin{array}{c}\text { Cooling jacket, painting the tank } \\
\text { white }\end{array}$ \\
\hline
\end{tabular}




\section{CHAPTER VI}

\section{CONCLUSIONS AND RECOMMENDATIONS*}

This thesis has investigated the utilization of flare streams for energy production using a cogeneration system and off-setting fuel gas as a way of reducing $\mathrm{CO}_{2}$ emissions. As assessment approach was developed and demonstrated by solving a base case study for producing 900,000 tons ethylene/yr. The process was first simulated. Sweetening and Claus processes were modeled to include in the energy and power study of the entire process (excluding cracking furnace). The heating and power requirements were found to be $36.81 \mathrm{MMBtu} / \mathrm{yr}$ and $32.016 \mathrm{MW}$, respectively. Three major flaring streams and their corresponding annual rates in the ethylene process were identified. The cogeneration system was designed to satisfy the heat requirement of plant and thereby produced $0.72 \mathrm{MW}$ of power. The environmental and economic analysis of this strategy showed $3.24 \times 10^{4}$ tons/yr reduction in $\mathrm{CO}_{2}$ emission and annual operational cost saving of $\$ 2.07 \times 10^{6}$ were realized due to reduced fuel gas consumption in the cogeneration system.

\footnotetext{
""Part of this chapter is reprinted with permission from "Managing abnormal operation through process integration and cogeneration systems" by Serveh Kamrava, Kerron J. Gabriel, Mahmoud M. ElHalwagi, Fadwa T. Eljack, 2014. Clean Technologies and Environmental Policy, pg. 1-10, Copyright [2014] by Springer Science+ Business Media"
} 


\section{REFERENCES}

Abdulrahman, R. K. and I. M. Sebastine (2013). "Natural gas sweetening process simulation and optimization: A case study of Khurmala field in Iraqi Kurdistan region." Journal of Natural Gas Science and Engineering14(0): 116-120.

Al-Azri, N., M. Al-Thubaiti and M. El-Halwagi (2009). "An algorithmic approach to the optimization of process cogeneration." Clean Technologies and Environmental Policy11(3): 329-338.

Bamufleh, H., J. Ponce-Ortega and M. El-Halwagi (2013). "Multi-objective optimization of process cogeneration systems with economic, environmental, and social tradeoffs." Clean Technologies and Environmental Policy15(1): 185-197.

Blomstedt, M., G. Nevestveit and P. Johansson, Operating with varying fuel properties without additional Wobbe-Index-measurement on SGT-600., Siemens Industrial Turbomachinery AB Sweden. http://www.energy.siemens.com. Accessed 29 June 2014.

Buzcu-Guven, B., R. Harriss and D. Hertzmark (2010). Gas Flaring and Venting: Extent, Impacts, and Remedies., Energy Study Working Paper-Energy Market Consequences of an Emerging US Carbon Management Strategy, Rice University, James Baker III Institute for Public Policy.

Crowl, D. A. and J. F. Louvar, (2011). Chemical Process Safety Fundamental with Applications, Pearson Education, Boston. 
Dar, H. J., S. U. Nanot, K. J. Jens, H. A. Jakobsen, E. Tangstad and D. Chen (2012). "Kinetic analysis and upper bound of ethylene yield of gas phase oxidative dehydrogenation of ethane to ethylene." Industrial \& Engineering Chemistry Research51(32): 10571-10585.

Davoudi, M., M. R. Rahimpour, S. M. Jokar, F. Nikbakht and H. Abbasfard (2013). "The major sources of gas flaring and air contamination in the natural gas processing plants: A case study." Journal of Natural Gas Science and Engineering13(0): 7-19.

Deneux, O., B. E. Hafni, B. Péchiné, E. Di Penta, G. Antonucci and P. Nuccio (2013). "Establishment of a model for a combined heat and power plant with thermosys pro library." Procedia Computer Science19(0): 746-753.

El'Terman, L. I., A. D. Stepukhovich and L. K. Bazhenova (1965). "Kinetics and mechanism of initiated decomposition of a propane-butane mixture at low pressures." Petroleum Chemistry U.S.S.R.4(4): 286-291.

El-Halwagi, M., D. Harell and H. Dennis Spriggs (2009). "Targeting cogeneration and waste utilization through process integration." Applied Energy86(6): 880-887.

El-Halwagi, M. M. (2012). Sustainable Design through Process Integration: Fundamentals and Applications to Industrial Pollution Prevention, Resource Conservation, and Profitability Enhancement. Elsevier, Waltham. 
Elliott, F. G., R. Kurz, J. P. O’Connell and C. Etheridge (2004). "Fuel system suitability considerations for industrial gas turbines." Journal of Engineering for Gas Turbines and Power126(1): 119-126.

EPA (2008) Catalog of CHP Technologies. U.S. Environmental Protection Agency Combined Heat and Power Partnership. http://www.epa.gov. Accessed 29 June 2014.

Farina, M. F. (2010). Flare Gas Reduction: Recent Global Trends and Policy Considerations., General Electric Company.

Froment, G. P., B. O. Van de Steene, P. S. Van Damme, S. Narayanan and A. G. Goossens (1976). "Thermal cracking of ethane and ethane-propane mixtures." Industrial \& Engineering Chemistry Process Design and Development 15(4): 495-504.

Fu, J. and Q. Xu (2013). "Simultaneous study on energy consumption and emission generation for an ethylene plant under different start-up strategies." Computers \& Chemical Engineering56(0): 68-79.

Hasan, M. M. F., I. A. Karimi and C. M. Avison (2011). "Preliminary synthesis of fuel gas networks to conserve energy and preserve the environment." Industrial \& Engineering Chemistry Research50(12): 7414-7427.

Heisel, M. P. and F. J. Marold (1987). "CLINTOX claus tailgas treatment." Gas Separation \& Purification1(2): 107-109.

Holmen, A., O. Olsvik and O. A. Rokstad (1995). "Pyrolysis of natural gas: chemistry and process concepts." Fuel Processing Technology42(2-3): 249-267. 
Jagannath, A., M. M. F. Hasan, F. M. Al-Fadhli, I. A. Karimi and D. T. Allen (2012). "Minimize flaring through integration with fuel Gas networks." Industrial \& Engineering Chemistry Research51(39): 12630-12641.

Jiang, X., P. Liu and Z. Li (2013). "A data reconciliation based approach to accuracy enhancement of operational data in power plants." The Italian Association of Chemical Engineering35: 1213-1218.

Kamrava, S., K. J. Gabriel, M. M. El-Halwagi and F. T. Eljack (2014) "Managing abnormal operation through process integration and cogeneration systems." Clean Technologies and Environmental Policy. 1-10.

Khan, F. I. and S. A. Abbasi (1997). "Mathematical model for HAZOP study time estimation." Journal of Loss Prevention in the Process Industries10(4): 249-257.

Labovský, J., Z. Švandová, J. Markoš and L. u. Jelemenský (2007). "Model-based HAZOP study of a real MTBE plant." Journal of Loss Prevention in the Process Industries20(3): 230-237.

Lippe, D. (2013). "2012 ethylene production bounces back; turnarounds in early 2013 to curb output." Oil \& Gas Journal111(3):72-81.

Liu, C. and Q. Xu (2010). "Emission source characterization for proactive flare minimization during ethylene plant start-ups." Industrial \& Engineering Chemistry Research49(12): 5734-5741. 
Mahnken, G. E. (2001). "Use case histories to energize your HAZOP." Chemical Engineering Progress97(3): 73-78.

Marhavilas, P. K., D. Koulouriotis and V. Gemeni (2011). "Risk analysis and assessment methodologies in the work sites: On a review, classification and comparative study of the scientific literature of the period 2000-2009." Journal of Loss Prevention in the Process Industries24(5): 477-523.

Muhammad, A. and Y. GadelHak (2014). "Correlating the additional amine sweetening cost to acid gases load in natural gas using Aspen Hysys." Journal of Natural Gas Science and Engineering17(0): 119-130.

Musyafa, A. and H. Adyagsa, (2012). "Hazard and operability study in boiler system of the steam power plant." IEESE International Journal of Science and Technology1(3): 110.

Patt, J. J. and W. F. Banholzer (2009). Improving energy efficiency in the chemical industry. National Academy of Sciences on behalf of the National Academy of Engineering.

Peters, M. S., K. D. Timmerhaus and R. E. West (2002). Plant Design and Economics for Chemical Engineers (Vol. 4). New York: McGraw-Hill.

Rahimpour, M. R., Z. Jamshidnejad, S. M. Jokar, G. Karimi, A. Ghorbani and A. H. Mohammadi (2012). "A comparative study of three different methods for flare gas 
recovery of Asalooye Gas Refinery." Journal of Natural Gas Science and Engineering4(0): 17-28.

Rahimpour, M. R. and S. M. Jokar (2012). "Feasibility of flare gas reformation to practical energy in Farashband gas refinery: No gas flaring." Journal of Hazardous Materials209-210(0): 204-217.

Rossing, N. L., M. Lind, N. Jensen and S. B. Jørgensen (2010). "A functional HAZOP methodology." Computers \& Chemical Engineering34(2): 244-253.

Shokrollahi Yancheshmeh, M. S., S. Seifzadeh Haghighi, M. R. Gholipour, O. Dehghani, M. R. Rahimpour and S. Raeissi (2013). "Modeling of ethane pyrolysis process: A study on effects of steam and carbon dioxide on ethylene and hydrogen productions." Chemical Engineering Journal215-216(0): 550-560.

Siemens AG (2007). Process Analytics in Claus Plants. www.industry.usa.siemens.com. Accessed 29 June 2014.

Sundaram, K. M. and G. F. Froment (1977). "Modeling of thermal cracking kinetics-II: Cracking of iso-butane, of n-butane and of mixtures ethane-propane-n-butane." Chemical Engineering Science32(6): 609-617.

UNEP (2006). Cogeneration. In: Thermal energy equipment. Energy Efficiency Guide for Industry in Asia. United Nations Environment Programme. www.energyefficiencyasia.org. 
Van Goethem, M. W. M., S. Barendregt, J. Grievink, P. J. T. Verheijen, M. Dente and E. Ranzi (2013). "A kinetic modelling study of ethane cracking for optimal ethylene yield." Chemical Engineering Research and Design91(6): 1106-1110.

Yang, X., Q. Xu and K. Li (2010). "Flare Minimization Strategy for Ethylene Plants." Chemical Engineering \& Technology33(7): 1059-1065. 